Anneliese Meis

Facultad de Teología

Pontificia Universidad Católica de Chile

\title{
El misterio de la alteridad en Alberto Magno Super Mysticam Theologiam Dionysii
}

La alteridad constituye una realidad compleja, que desde siempre suscita interés, debido a que su extraña densidad conceptual tiene una singular repercusión vital. Desafía cualquier forma de pensar -Denkform-, también aquella de Alberto Magno, cuyo Comentario Super Mysticam Theologiam Dionysii, un texto excepcionalmente breve (1), será el objeto del presente estudio. En efecto, la alteridad evoca un fenómeno multifacético, de significaciones no siempre fáciles de traducir, pero que desde dentro se compenetran, como ya lo enuncia el origen etimológico de alter-alius, completado por $\dot{\tau} \varepsilon \rho \rho v(2)$, términos cuya frecuencia estadística constituye la base del esfuerzo metódico por realizar. Además, el Doctor Universalis depende de la Mystica Theologia de Dionisio, pensador intencionalmente oscuro, por lo cual la estructura mental albertina resulta más compleja de lo que parece, lo cual recién se está descubriendo en cuanto a su extraordinaria capacidad teológica sistemática (3).

Si bien el presente estudio va en busca de la mystice intelligentia, expuesta en el Super Mysticam theologiae, atestigua que la razón humana llega a sus límites allí donde pretende obtener una racionalidad teológica sistemática coherente. Además, la percepción de dichos límites se radicaliza por la censura, que prohíbe el

(1) AlBERTi MAGNI, Omnia Opera (XXXVII, 2) 1978, 452-487; WEBER E. H., Commentaire de la Théologie mystique de Denys le Pseudo-Aréopagite suivi de celui des Epîtres I-V / Paris 1993, 267 pp: Albert the Great, Commentary on Dionysius "Mystical Theology", traslated, edited, and introduced by SIMON TUGWELL, en Albert/Thomas, Selected Writings, New York 1988, 3-198.

(2) Cf. ERNOUT A., MEILlET A., Dictionnaire de la langue latine. Histoire de mots, Paris 1932, p. 32-34. Sucede que la distinción entre alius y alter y ceterus no es rigurosamente observada. Mientras alius dice una cosa, otro, otra cosa y también puede significar "diferente", alter designa "un otro" en oposición a un individuo determinado.

(3) ANZULEWICZ H., Die Denkstruktur des Albertus Magnus. Ihre Dekodierung und ihre Relevanz für die Begrifflichkeit und Terminologie, in L'elaboration du vocabulaire philosophiques au Moyen Age, HAMESSE J., STEEL (eds.) Tourhout 2000, 369-396; CRAEMER-RUEGENBERG I., Albertus Magnus. Völlig überarbeitete, aktualisierte und mit Anmerkungen versehene Neuauflage der Originalausgabe, herausgegeben von ANZULEWICZ Henryk (Dominikanische Quellen und Zeugnisse, 7) Leipzig 2005, 228 pp; RUH K., Geschichte der abendländische Mystik III, München 1996, 57-163. 
estudio de Dionisio en la Universidad de París desde 1241 (4). Tal censura origina aquella reacción peculiar de Alberto, quien reconoce, por un lado, la dificultad que emana de la oscuridad de la obra dionisiana para cualquier lector respecto de posibles efectos negativos sobre la comprensión del dogma; y, por otro, que los beneficios de tal lectura son innegables, ya que favorecen un quehacer teológico humilde y afectuoso, apoyado en la capacidad connatural de la razón humana, aunque ella experimente sus límites. Para entender tal dilema cabe evocar las diversas posturas que contextualizan el esfuerzo albertino, en cuanto síntesis del antiquísimo problema de la relación razón y amor, problema que emerge del Banquete de Platón, allí donde el filósofo describe el ascenso de la razón humana a la belleza, apoyada en el amor-eros, y advierte que dicha belleza irrumpe, de repente, en el preciso momento en que la razón llega a sus límites, límites sobrepasados por el amor, es decir, el eros logra aquello que a la razón no le es posible .

Esta versión fundamental del problema razón y amor se plasma a través de infinitas variantes a lo largo de la historia del pensamiento humano, para adquirir una densidad inaudita en el contexto histórico inmediato de Alberto Magno -siglos XII y XIII- donde confluyen la tradición griega -Orígenes y Gregorio de Nisa-, y la latina -Agustín y Gregorio Magno- en la conocida fórmula: Amor ipse intellectus est. La finura conceptual de los autores señalados se torna compleja en Guillermo de Saint Thierry y Ricardo de San Victor, teniendo su representante más conocido en Buenaventura, pensadores enjuiciados, con frecuencia, como si estuvieran dividiendo o confundiendo razón y amor, de tal modo que serían ellos los adversarios contra los cuales Alberto Magno apunta en su STM. De hecho, los verdaderos contradictores del Doctor Universalis son Thomas Gallus, con su comprensión de la scintilla synderesis, ordenada a la affectio principalis y capaz de unirse a Dios (5) y Hugo de Balma, de mayor influencia por su Comentario a la Mystica Teología (6). Estos autores tratan de penetrar en los misterios de la obra dionisiana, del mismo modo que Alberto Magno, pero parten de una precomprensión diferente, es decir, se muestran despreocupados por la racionalidad teológica de la mística. Tal escisión entre teología y mística está totalmente ausente en el esfuerzo científico de Alberto, quien, aun siendo extremadamente fiel a Dionisio (7), elabora una visión sistemática de la teología que debe ser mística o no es teología.

No cabe duda de que tal esfuerzo albertino no es fácil de comprender, sobre todo cuando compromete la precomprensión de la teología contemporánea en sus avances hermenéuticos. Por eso, las interpretaciones del pensamiento de Alberto son diversas en lo referente a la racionalidad propia del SMT (8). De todos modos, se perfilan dos estudios sobresalientes, el de Edouard Henry Wéber y William Hoye.

(4) TUGWELL, S., o. c., 39-95; 116-129.

(5) Los escritos de Thomas Gallus despertaron mucho interés en 1220.

(6) HUGUES DE BALMA, Théologie Mystique I y II, Introducción RUELLO F., (SC 408/409) Paris 1995, escrito a fines del siglo XIII y durante mucho tiempo considerado una obra de Buenaventura.

(7) ANZULEWICZ H., Pseudo-Dionysius Areopagita und das Strukturprinzip des Denkens von Albert dem Grossen, en: Die Dionysius-Rezeption im Mittelalter BOIADJIEV T., KAPRIEV 7 SPEER A. (eds.), Tournout 2000, 251-295.

(8) RUH K., Geschichte der abendländische Mystik, 113-163. 
Edouard Henry Weber, especialista renombrado de Alberto Magno, centra su análisis en la luz, el lumen fidei, considerando clave este concepto para solucionar el impasse que se produce al interior de la unión entre Dios y el hombre, cuando este trata de comprender, racionalmente, a Aquel. En numerosos estudios específicos, el erudito francés aporta luces significativas para la comprensión de la argumentación albertina a partir del mencionado concepto lumen fidei (9), es decir, la luz participada por el intelecto humano posibilita, de algún modo, una intelección divina. No cabe duda de que se trata de una solución relevante, pero, que, desgraciadamente, se basa en una única cita, que aparece en un contraargumento del $S M T$, es decir, que, según el método aplicado por Alberto, no expresa el pensamiento propio del Doctor universalis.

Es lo que advierte William Hoye, estudioso germano, también medievalista (10), quien, a su vez, propone una respuesta propia, recurriendo a la importancia metódica de la "negación intelectual" y la distinción consecuente entre lo "natural" y "sobrenatural". Dicha respuesta se centra en el mismo intelecto humano, donde acontece el encuentro entre el sujeto cognoscente y Dios, el Otro por excelencia, de tal modo que oportet per intellectu uniri deo (11). Sin duda, Hoye presta especial atención a la complejidad del intelecto humano, sus posibilidades y límites, pero mientras Weber, junto con exponer su propia solución, concede validez a la relevancia del amor, aunque dando preferencia a la fe, el estudioso alemán niega dicha relevancia para la racionalidad albertina del SMT. Con esto, quedan sin explicación aspectos que no se considera propios de la razón humana, pero que el Doctor universalis integra hábilmente en su comprensión "intelectualista", la dimensión "afectiva" (12). De ahí que urge una revisión de la argumentación de Alberto Magno en el SMT.

Si bien la presente investigación no pretende discutir alcances detallados de los estudios señalados, aunque sorprenden apreciaciones poco precisas tanto respecto de Guillermo de Saint Thierry, como de Ricardo de San Victor, pero sobre todo de Buenaventura -autores de gran originalidad racional, valorados, actualmente, con mayor acierto, en su contribución metafísico científica-, ella llevará a cabo una lectura analítica del texto original, que lleva las soluciones de los autores mencionados hacia una nueva propuesta. Sostiene que el eje de la argumentación se encuentra en el misterio de la alteridad, articulado al interior del intelecto humano y como tal capaz de integrar aquellos aspectos afectivos, disonantes con el rigor racional albertino, pero que constituyen la identidad del sujeto cognoscente, en cuanto esta se debe a Otro.

(9) WEBER E-H., L'Interpretation par Albert Le Grand de la Théologie Mystique de Denys Le PsAréopagite, en MEYER G., ZIMMERMANN A. (eds.) Albertus Magnus Doctor Universalis 1280/1980, Mainz 1980, 409-439; WEBER E. H., L'Apophatisme Dionysien chez Albert le Grand et dans son École, en ANDIA Y. DE., Denys 1'Areopagite et sa posterité en Orient et en Occident, Paris 1997, 379-403.

(10) HOYE W., Mystische Theologie nach Albert dem Grossen, en SENNER W., ANZULEWICZ H. (eds.), Albertus Magnus. Zum Gedenken nach 800 Jahren: Neue Zugänge, Aspekte und Perspektiven, Berlin 2001, 587-603.

(11) 465, 8 Cf. Unitio intellectiva 460, 7.

(12) Alberto define la Teología una "scientia affectiva" en In Sententiarum d.1 a. 4.S.19a. Cf. CRAEMER-RUEGENBERG I, o. c., 55; 60s; 169. 
Tal deberse a Otro conlleva un cuestionamiento intrínseco de la diferencia misteriosa de dicho Otro con respecto al sujeto cognoscente. Pues, ¿cómo acontece el misterio, si no es fundando la diferencia en su carácter de origen fundante, ya que ella a su vez ha sido fundada, fundación entonces redoblada en doble instancia? En efecto, la diferencia entre alteridad e identidad se encuentra sostenida por una diferencia mayor, la alteridad por excelencia, el Otro, Dios. Introducir a Dios en un planteamiento metafísico parece ser una onto-teología desechable, con justa razón, si no se advierte que Dios no es el ser, sino Quien lo da, es decir, se encuentra "más allá del ser", a la vez que constituye dicho ser en la identidad singular, de modo siempre desbordante (13).

Cabe preguntar: ¿habrá una presencia anticipatoria, que urge al intelecto a buscar un camino donde no hay camino, ya que el Dios oculto le es connatural a modo no proporcional? ¿Habrá algún anhelo recóndito en el sujeto, un desiderium, que insinúa que lo anhelado -el "Dios oculto"- no le es tan extraño al intelecto humano como parece, o ¿es simplemente Dios quien atrae al hombre hacia Sí al sobrepasarlo? Estas son las preguntas a las cuales estará atenta la presente investigación, al abordar los alcances filológicos de aquellos términos que configuran la alteridad y los trasciende hacia el significado teológico del misterio, que permite captar hasta qué punto la identidad se constituye por medio de la alteridad, siendo ella siempre desbordante con respecto de aquella. De ahí que se procede a analizar el campo semántico del vocablo myst-, para pasar a sondear el de alter-aliud, y verificar el nexo entre ambos a partir de la partícula $a d$, de peculiar relevancia para el modo de pensar que expresa aquella finalidad, distintivo más relevante de la teología de Alberto Magno (14).

\section{EL MISTERIO DEL DIOS OCULTO Y SUS IMPLICACIONES METODOLÓGICAS}

Alberto Magno abre su Comentario con una referencia del traductor a la índole mística de la doctrina que expone Dionisio en su Mystica Theologia, a partir de la cual emerge el "Dios oculto" como el objeto central de dicha doctrina. Este "Dios oculto" constituye aquella dimensión de la alteridad a causa de la cual la doctrina que se pretende aprender se llama mística, esto es, oculta, "porque a través de ella se asciende por la negación al conocimiento de Dios y finalmente lo que Dios es, permanece sellado y oculto" (15). Esto significa, que Dios es y sigue siendo el Otro inconocible, pero alcanzable por el ascenso a través de su conocimiento, esto es, "por medio de la negación". Tal ascenso, figura mental antiquísima del pensamiento humano, permite a la razón humana acercarse a lo no-acercable, es decir, al Dios

(13) KÜHN R., Principium individuationis als Ontologiekritik, Freiburger Zeitschrift für Philosophie und Theologie 52 (2005) 171-190. RICOEUR P., Sí mismo como otro, Madrid 1996, 415 pp.

(14) Cf. TROTTMANN C., La théologie comme pieuse science visant la béatitude selon Albert le Grand, Revue Thomiste 98 (1998) 559-588.

(15) 453, 20-25: Materia autem huius doctrinae tangitur in hoc quod dicit "deus absconditus". Dicitur enim mystica, idest occulta, ut in PROOEMIO TRANSLATOR dicit, "quia cum iuxta eam per ablationem ad dei scientiam ascenditur, tandem, quid sit deus, clausum et occultum relinquitur". 
oculto. Con esto lleva a aquella faceta básica, que marca la alteridad como imposibilidad de ser conocida, a la vez que posible por medio del ascenso de la negación. Pero ¿por qué Alberto insiste en el ascenso al conocimiento -scientia- de Dios y no simplemente a Dios? La scientia parece constituir, entonces, una especie de nexo entre Dios y el hombre, polos ambos que, más que una polaridad opuesta, incomunicable, se abren a una comunicación posible, aunque desigual.

Pero, ¿de dónde viene esta insistencia en la scientia y la necesidad de acceder a ella? Alberto recurre, sin duda, a textos bíblicos incuestionables para verificar la dimensión oculta de Dios en cuanto revelado. Esto le permite al autor poner bases sólidas para avanzar por el camino de la negación propuesto por el texto dionisiano. Pero ¿qué es lo que se niega?, ¿a partir de qué? ¿Y por qué? Estas son las preguntas preliminares que configuran la dimensión mística de la alteridad, abordadas por Alberto por medio de argumentos en contra y a favor, acorde al método escolástico empleado y que hace preguntar más a fondo por "el nombre de esta ciencia y por qué se llama mística, en el cual se abre su finalidad-intentio" (16). Cabe fijarse, brevemente, en aquellos aspectos místicos que resaltan los contraargumentos, soluciones y confirmaciones para descubrir una primera articulación del misterio de la alteridad en el STM.

\section{a) El conocimiento místico del Dios oculto en los contraargumentos}

Con el primer contraargumento se cuestiona la posibilidad de la ciencia mística desde el concepto de ciencia, es decir, pareciera que ninguna ciencia debe ser llamada mística; pues todo lo que es conocido ha sido puesto al descubierto desde sus principios; lo que es puesto al descubierto no está oculto; luego, pareciera que ninguna ciencia ni esta ciencia deba llamarse mística u oculta (17). Esta apreciación se basa en la comprensión aristotélica de ciencia, en cuanto ella pretende reconducir todo a sus primeros principios, a resultados claros y distintos. De tal modo, lo oculto deja de ser oculto, es decir, no respeta la alteridad, por lo cual la ciencia mística resultaría imposible, ya que la ciencia procede de modo categorial, sin tomar en cuenta la anticipación trascendental de la alteridad divina.

Sin embargo, Alberto no se contenta con esta conclusión, sacada grosso modo, en contra de una ciencia mística, que la deja sin validez científica, sino que hila más fino al evocar otro contraargumento que evidencia ciertos grados en lo referente a la índole mística de la ciencia, grados que van creciendo en la medida en que se abordan "las cosas sensibles". Estas permiten un acercamiento científico a Dios, conservando una cierta índole mística, pero, a su vez, superada por otra realidad más oculta, proveniente de la doctrina de "las personas" en Dios, pues: "aquello que está totalmente oculto más es llamado místico que aquello que es manifiesto en cuanto a su principio; pero las negaciones respecto de Dios, desde las cuales procede esta ciencia, como es dicho en el capítulo tercero, proceden de las cosas sensibles que

(16) $454,14:$ His igitur praelibatis quaerendum est de nomine istius scientiae, quare mystica dicatur, in quo et intentio eius aperietur.

(17) 454, 17- 20 (1) Videtur enim, quod nulla scientia debeat dici mystica; omne enim quod scitur, ex principiis suis in aperto ponitur; quod autem in aperto positum est, non est occultum; ergo videtur, quod nulla scientia nec ista scientia debeat dici mystica vel occulta. 
son descartadas de Dios. En cambio, las personas divinas, que son tratadas en otra doctrina, son del todo ocultas; por esto pareciera que aquella doctrina con mayor razón que esta debe ser llamada mística (18). Alberto distingue aquí entre una doctrina que lleva a un cierto conocimiento de la existencia de Dios a partir de los efectos y la otra -alia- doctrina, cuyo eje central lo constituyen "las personas divinas", que atestiguan un grado mayor de alteridad, del todo oscuras para la racionalidad aristotélica.

Tal grado de alteridad ad intra y, por eso, "más mística" que la existencia de Dios, lo profundiza Alberto en otro contraargumento cuando, sirviéndose de una cita de Ambrosio, trastoca el "más" del contraargumento anterior en un "máximamente", aseverando: aquello debe ser llamado máximamente místico u oculto, cuanto máximamente queda remoto de nuestro conocimiento; pero la distinción de las personas está máximamente remota de nuestro conocimiento; como dice Ambrosio: “(...) Me es imposible saber el secreto de la generación; la mente fallece, la voz se calla, no tanto la nuestra, sino también la de los ángeles". De ahí, pues, parece que aquella doctrina en la cual se hace esta distinción de las personas, debe ser llamada máximamente mística" (19). No cabe duda de que la mente-intelecto -tanto humana como angelical-, llega a su límite extremo, pues deja de ser lo que es por naturaleza, logos-habla, y se calla ante el totalmente otro, Dios, en la constitución de su ser más íntimo, la generación del Verbo.

Sin embargo, dicha "generación”, atestiguada por la Revelación del Dios-Otro, es decir, aquella posibilidad divina de ser Logos por excelencia, procura al intelecto creado un nexo fundante a partir del preciso momento de sucumbir este en el vértice de lo "místico", cuando el Logos de Dios se une al intelecto creado por la encarnación. Significa, según Agustín, que Platón todavía puede intuir cierta racionalidad en la existencia del Logos de Dios en el principio; la encarnación, por su parte, conlleva una oscuridad mística máxima, que el filósofo no comprenderá, pues: aquello que es dicho por Juan en el PRINCIPIO, se puede leer del mismo modo en los libros de Platón. Sin embargo, aquello que se dice: "el Verbo se hizo carne" allí no se encuentra; de donde se dice de él que lo que tiene de sacramento: "el Verbo se hizo carne", ni siquiera se puede sospechar, porque aquello a lo cual menos pueden llegar los filósofos más oculto está a la razón humana. Por tal razón, como el misterio de la encarnación es trasmitido por parte de Dionisio en otra doctrina con las distinciones de las personas, así como se indica en el libro De Divinis Nominibus, en el capítulo de la Paz, parece que aquella ciencia máximamente debe llamar-

(18) 454, 22-29 (2): illud quod est totum occultum, magis est dicendum mysticum quam illud quod quantum ad principium sui est manifestum; sed negationes de deo, secundum quas procedit ista scientia, sicut in Tertio Capitulo dicitur, procedunt a manifestatis sensibilibus quae removentur a deo; divinae autem personae, de quibus agitur ab ipso in alia doctrina, sunt ex todo occultae; ergo videtur, quod illa doctrina magis debeat dici mystica quam ista.

(19) 454, 30-37 (3); illud maxime debet dici mysticum vel occultum quod maxime est remotum a cognitione nostra; sed distinctio personarum maxime remota est a cognitione nostra; unde dicit AMBROSIUS: "Mihi impossibile est scire generationis secretum: mens déficit, vox silet, non nostra tantum, sed et angelorum"; ergo videtur, quod illa doctrina in qua agitur de distinctione personarum, maxime debeat dici mystica.Para el concepto remotio Cf. DE ANDIA Y., Remotionegatio.L' Évolution du vocabulaire de saint Thomas touchant la voie négative, AHDLMA 68 (2001) 45-71. 
se mística (20). El misterio de la Encarnación y su relación con las propiedades de las personas emerge aquí como vértice de oscuridad mística, lo cual no deja de ser soprendente y paradójico, ya que la alteridad divina aparece plasmada en los contornos concretos de un hombre.

Aquí se aprecia que la índole mística de la alteridad para Alberto no se restringe al mero adjetivo, sino que se plasma a través de un sustantivo multifacético y profundamente bíblico, el Misterio. Así lo da a entender también la invocación de la cita joánica Jn 1, 14, por la cual el enfoque de la argumentación deja de ser netamente metafísica y se torna teológica cristológica. Esto se percibe cuando el autor prosigue adentrándose en la oscuridad más profunda de la doctrina mística. Evoca las propiedades de las personas divinas, a la vez que recuerda las apropiaciones. Mientras aquellas no son pensables por los filósofos, estas últimas, sí, pues Alberto continúa, contraargumentando: Además de esto, como dijimos, los filósofos tuvieron algún conocimiento de las divinas personas por las apropiaciones, sin embargo, lo propio de ellas no se puede conocer de ningún modo; por eso, parece que la ciencia que habla de las propiedades mismas, debe ser llamada máximamente oculta y mística (21).

Recordando que la certeza de la ciencia procede de los principios y como tal divide la ciencia en oculta y manifiesta, Alberto constata que la ciencia de los nombres divinos en cuanto a sus principios es oculta, la cual muestra de qué manera todo procede desde lo oculto de la divinidad y se manifiesta a nosotros. Por lo tanto, aquella doctrina más debe ser llamada mística que esta (22). Si bien resalta aquí la relevancia de la certeza de aquella ciencia que parte de los sentidos y que la de los nombres debe considerarse sumamente mística, en el sentido dionisiano, Alberto precisa todavía un aspecto más englobante de la índole mística de tal ciencia, cuando su contraargumento se desplaza del énfasis sobre el método y contenido hacia la causa última de la dimensión mística, su origen propiamente tal. Pues, aquello que es sobreeminente a todos los entes, resta oculto para nuestro conocimiento, de cuya causa proviene la existencia; pero en el libro De Divinis Nominibus el autor enseña exponer todo nombre divino por eminencia; entonces, aquella cien-

(20) 454, 45; 49(4): sicut dicit AUGUSTINUS, quod cum alia quae dicuntur in PRINCIPIO IOH., legerit quodam modo in libris Platonis, tamen hoc quod dicitur "verbum caro factum est", ibi non invenit; unde de ipso dicitur, quod quid sacramenti haberet "verbum caro factum est", nec suspicari quidem poterat; sed illud ad quodo minus possunt philosophiae pervenire, magis est occultum a ratione humana; ergo cum mysterium incarnationis traditum sit a Dionisio in alia doctrina cum distinctivis personarum, sicut innuit in libro DE DIVINIS NOMINIBUS in CAPITULO DE PACE, videtur, quod illa scientia maxime debeat dici mystica. De todos modos, este misterio se presenta aquí como causa de que la ciencia sea máximamente llamada mística.

(21) 454, 50-54 (5): quamvis dicamus, quod PHILOSOPHI habuerunt aliquam cognitionem de divinis personis per appropriata, tamen propria ipsarum nullo modo cognoverunt; ergo videtur, quod scientia, quae est de ipsis propriis, maxime debeat dici oculta et mystica.

(22) 454, 57-62 (6): tota certitudo scientiae procedit ex principiis; scientia ergo, quae quantum ad principium sui est occulta, magis debet dici mystica quam quae quantum ad principium sui est manifesta; sed ista scientia quantum ad principium sui est manifesta, quia procedit incipiens a sensibilibus, removendo ea a deo; scientia autem de divinis nominibus quantum ad principum sui est occulta, quia ostendit, qualiter ab occulto divinitatis omnia manifesta nobis procedunt; ergo illa doctrina magis debet dici mystica quam ista. 
cia debe ser llamada mística (23). La sobreeminencia de la causa divina con respecto a todo lo creado, es, entonces, causante de la oscuridad del conocimiento humano. Pero el autor evoca la existencia y los nombres de Dios ya no en clave de superlativo, sino de una simple constatación de lo "oculto y místico".

Alberto, a diferencia de Dionisio, vuelve, una vez más, desde lo manifiesto a lo oculto, cuando, basándose en el Capítulo II y I de la Caelestis Hierarchiae, insiste en el carácter simbólico de la Sagrada Escritura, pues: la Sagrada Escritura nos describe lo divino por símbolos, para que proporcionalmente para nosotros por aquellas cosas que nos son conocidas seamos reconducidos a las divinas. Si, por tal razón, esta ciencia debe llamarse mística, porque nos conduce desde lo manifiesto y nos deja en lo oculto, parece que, también a causa de este fin oculto, la teología símbólica debe ser llamada mística (24). Este último contraargumento procede desde los símbolos, pero tomando en cuenta la proporcionalidad de estos símbolos con respecto a las cosas divinas en cuanto posibilidad que ellos brinden para reconducir todo a Dios. Sin embargo, ¿el movimiento desde lo manifiesto a lo oculto no será el que impregna todo el pensamiento de Dionisio, pero no el de Alberto? Por eso, hay que seguir de cerca la argumentación albertina para descubrir los matices en los argumentos a favor del conocimiento místico de Dios.

\section{b) Los argumentos a favor del conocimiento místico del Dios Otro}

En la medida en que Alberto avanza en la comprensión de la índole mística de la doctrina dionisiana de Dios (25), trata de dilucidar lo que se refiere a la verdad de las personas divinas, es decir, se detiene en lo "máximamente oculto" para hacer la siguiente distinción: "dado que las divinas personas están ocultas en su realidad propia, de todas maneras el modo de tratarlas no es oculto, porque, de hecho, en aquella doctrina se afirma algo de este sujeto, por ejemplo, que el Padre engendra o que hay tres personas, todo lo cual conduce a nuestro intelecto a extraer de lo oculto de la divinidad las cosas manifiestas, en las que se observa un índice de lo que en ellas se encuentra de la primera causa. Por el contrario, esta ciencia es llamada mística del punto de vista de su método" (26). Puede apreciarse aquí la distinción entre la verdad en sí -el Dios-Otro- y la manera de tratarla, es decir, el método que procede desde nosotros y nuestro intelecto. Esta distinción la avala

(23) 454, 65-69 (7): illud quod supereminet omnibus entibus, est occultum nostrae cognitioni, cuius causa sunt existentia; sed in libro DE DIVINIS NOMINIBUS docuit exponere omnia nomina divina per eminentiam; ergo illa scientia debet dici mystica.

(24) 454, 74-77(8): sicut dictum est in SECUNDO ET PRIMO etiam CAPITULO CAELESTIS HIERARCHIAE, sacra scriptura describit nobis divina per symbola, ut proportionaliter nobis per ea quae nobis sunt nota, reducamur in divina; si igitur esta scientia debet dici mystica, quia ducit nos a manifestis et reliquit nos in occulto, videtur, quod etiam propter finem occultum symbolica theología debeat dici mystica.

(25) 455, 8: quia ista doctrina considerat huiusmodi remotionem quae est per negationes, aliae autem considerant affirmationes de deo, ista magis debe dici mystica quam aliae, ex hoc quod in occulto nos relinquit, aliae autem ex occulto nos trahunt in manifesta.

(26) $455,33-37(2)$ quia per hoc quod affirmatur aliquid de eis in illa doctrina, ut quod pater generat vel quodo sunt tres personae, trahitur intellectus noster ex occulto deitatis ad res manifestas, in quibus aliquod indicium invenitur, relictum in eis ex causa prima. Haec autem scientia dicitur mystica quantum ad modum, ut DICTUM est. 
Alberto por tres verdades, el ejemplo del Padre, quien engendra, el hecho de que hay tres personas en Dios y el índice de la primera causa. Por cierto, el hecho de que el Padre engendra tiene una repercusión primordial sobre nuestra capacidad cognoscitiva, ya que ella, al "extraer las cosas manifiesta de lo oculto de la divinidad", atestigua una participación en dicho engendrar, origen de las tres personas divinas, de tal modo, que la primera causa se hace visible a través de la racionalidad propia del intelecto humano.

Alberto especifica esta racionalidad cuando aborda los nombres divinos, que atestiguan una llamativa índole oculta, pero cuya intelección se podrá lograr a partir del acercamiento metódico adecuado desde la finalidad de la ciencia. De hecho: "la ciencia de cualquier clase debe denominarse a partir de la meta final, el fin; y por eso esta ciencia que permanece en su fin oculta, debe ser llamada más todavía mística que la ciencia a partir de los nombres divinos, la que expone un proceso que parte desde lo oculto a lo manifiesto, principalmente cuando también el principio no es considerado así como oculto, a fin de que se manifieste por la procesión de las cosas a partir de él, la conveniencia según la proporción de la imitación acorde con él"(27). Resulta significativo, como una aproximación científica, que admite la orientación innegable de la ciencia por su fin, posibilita la comprensión adecuada de la verdad de los nombres divinos, precisamente en cuanto proporcional al fin que está oculto, pero que se revela por medio de la "procesión de las cosas", es decir, se abre desde lo oculto hasta lo manifiesto, sin que la alteridad pierda su índole mística.

Si bien tal índole se extiende, dinámicamente, hacia el fin, acorde al ritmo característico para el pensamiento albertino, ella requiere "la conveniencia según la proporción de la imitación acorde con él", para su adecuada articulación. Con esto Alberto subraya tres ideas claves respecto de la comprensión de la alteridad divina: la conveniencia, la proporción y la imitación, conceptos todos ellos que en su conjunto componen el campo semántico de la analogía albertina (28). Surge la pregunta: ¿de qué analogía se trata? ¿Cómo se aplica convenientemente? ¿De dónde esta curiosa combinación entre proporción e imitación? ¿De qué proporción, de qué imitación se trata? No se vislumbra aquí la respuesta de Alberto a tales preguntas, pues el autor prosigue con su argumentación, centrada en aquella oración, con que Dionisio abre su MT: "dirígenos al sumo vértice de las escrituras místicas, según lo que en todas las negaciones relativas podemos acceder en lo oculto a este vértice, digo, superignoto, etc., esto es, en el vértice donde los misterios de la Palabra divina son ocultos, esto es, escondidos ante nosotros, según la tiniebla espesa del docto silencio, superesplendorosa secretamente (29). Alberto, junto con mencionar "el sumo vértice de las escri-

(27) 455, 41-47(6): ideo ista scientia, quia relinquit in fine occulto, magis debet dici mystica quam scientia de divinis nominibus, quae ostendit processum ab occulto in manifestum, praecipue cum etiam principium non consideraretur ibi ut occultum, sed ut manifestatur per processionem rerum ab ipso, convenientium secundum proportionem imitationis cum ipso.

(28) LIBERA, A. de Albert le Grand et la Phillosophie, Paris 1990, 80-101.

(29) 457, 12-17 dirige nos ad summum verticem mysticorum eloquiorum, secundum quod in negationibus omnium in ipsum quasi in quoddam occultum venimus, ut DICTUM EST, verticem, dico, superignotum, etc. ubi, idest in quo vertice, mysteria theologiae sunt cooperta, idest abscondita a nobis, secundum caliginem docti silentii, supersplendentem occulte. 
turas místicas" del texto dionisiano y las "negaciones", que permiten acceder a dicho vértice, se fija aquí en "los misterios de la Palabra divina", ocultos en el "vértice superignoto", es decir, "escondido ante nosotros". Resalta la Palabra divina, pero también sus "misterios". Siendo fiel a la comprensión básica de lo místico, Alberto designa estos misterios "ocultos", pero explica que esto significa "escondidos ante nosotros", acorde a la índole propia de la "tiniebla espesa, superesplendorosa", paradoja, por cierto, frecuente en la literatura mística.

Tal paradoja Alberto la explica por medio de la metáfora antigua del ojo cegado por la sobreabundancia de luz, para volver, de inmediato, sobre los "misterios de la Palabra", diciendo: A causa de esta noche oscura los misterios divinos son ocultos para nosotros, misterios, digo, que son simples, etc., que llamo vértice, porque en la inteligencia ellos resplandecen desde lo alto y muy claramente la luz divina en la noche muy oscura de la eminencia divina. Bien que del hecho de la oscuridad provocada en nosotros por la eminencia del esplendor de Dios somos deficientes en cuanto a la comprensión de esta trascendencia, sin embargo, parece que nos adherimos de una cierta manera al trascender todas las cosas, nuestra inteligencia es deificada e iluminada (30). Alberto explica aquí la oscuridad de los Misterios no solo a partir de la incapacidad del intelecto para tanta luz, sino a causa de su índole "simple" y como tal estos misterios son vértice, lo cual significa que ellos resplandecen en la inteligencia "desde lo alto", de tal modo que muy claramente la luz divina resplandece en la noche muy oscura de la "eminencia". Cabe advertir la preferencia albertina respecto de la luz.

Si bien la eminencia causa la oscuridad del intelecto humano, esto no significa su anonadamiento. Por el contrario, este termina adhieriéndose vigorosamente al Dios trascendente, totalmente otro, en cuanto inteligencia "deificada e iluminada". Resalta así el paso de la índole mística, es decir, del adjetivo a "los misterios", el substantivo en plural. Estos "misterios" se encuentran interrelacionados con la "Palabra divina", es decir, la argumentación albertina sale de un enfoque más general del ser de Dios para detenerse en lo particular, la Palabra. Se trata, por cierto, de un momento "vértice", que resalta el superlativo, la índole de sobreeminencia, pero que interrelaciona lo visto con lo escuchado, el esplendor sobreesplendoroso, con el docto silencio. Esta interrelación entre el sentido del ojo y del oído, ciertamente es permanente en la argumentación de Alberto, de donde brota también la insistencia en la adecuada preparación del sujeto de tal ciencia, pues: "La ciencia mística debe guardarse de entregar esta ciencia divina al conocimiento de algún ignorante" (31). Se trata aquí de un conocimiento para el cual no todos son aptos. Pero tal aptitud sujetiva no es segregativa o constitutiva, sino que se apoya más bien en una adecua-

(30) $457,18-29 ; \ldots$ sicut enim ex nimio solis splendore efficitur quaedam tenebrositas in oculto debili nulla caligine in sole existente, ita "in deo tenebrae non sunt ullae", sed ex nimio ipsius splendore obtenebratur noster oculus quia impotens est ad tantum splendorem, et per istam caliginem occultantur divina a nobis, mysteria, dico, simplicia etc, verticem dico, facientem desuper splendere in mentem superclarissimum quoddam, scilicet divinum lumen, in obscurisimo divinae eminentiae, quia quamvis per obscuritatem relictam in nobis ex eminentia splendoris deficiamus a comprehensione divinae eminentiae, tamen ex hoc quod attingimus aliqualiter ipsam relictis omnibus, mens deificatur et illuminatur.

(31) 458, 33; 38: Dicit ergo primo, quod hic cavere debet, ne aliquis indoctus in divina doctrina audita ista mystica... idest sine proportione ad ipsa. 
da preparación. Con esto la argumentación albertina entra en una profundidad mayor, que se descifra detenidamente, por un esfuerzo de comprender no solo la índole mística o los misterios divinos, sino el misterio de Dios en cuanto Misterio del Verbo encarnado.

\section{c) El misterio del Verbo de Dios encarnado}

Cuando Alberto en su esfuerzo por dilucidar una comprensión cada vez más adecuada de la alteridad divina, en sí inasequible, pero asequible "para nosotros", se detiene en el mismo misterio de Dios, tal como este emerge del Evangelio, donde está escrito, que nosotros no nos servimos de la teología, esto es, el sermón de Dios que es absolutamente mayor, en consideración al efecto y a las figuras y es más breve en cuanto a lo que en el estado peregrino de la vida podemos captar de Dios; y especialmente en el Evangelio, en el cual se encuentra la doctrina del Verbo Encarnado, dice que es largo por causa de la multitud de las parábolas, y es grande por causa de la profundidad de la ciencia y de los misterios, y, sin embargo, conciso, esto es, breve, en cuanto a que esto es para manifestarnos a Dios a nosotros mismos, del que nunca podemos captar por igual (32). La insistencia del autor en el Evangelio resalta la grandeza desbordante del sermón de Dios en sí y "en consideración al efecto y las figuras”.

Sin embargo, Alberto advierte una adecuación llamativa a nuestro intelecto "en el estado peregrino": por la brevedad condensada de la realidad de Dios en el Verbo encarnado, los misterios de Dios, desbordantes, "nunca por igual", se hacen captables "para nosotros "en su manifestación que Dios origina por la índole concisa y breve de su Sermón. Resalta Alberto la extraordinaria profundidad de estos misterios, múltiples en sus expresiones y grandiosos por su profundidad. Tal profundidad requiere del sujeto cognoscente una purificación radical, "la entrada en la nube expresa", entrada en el "misterio de gran significación", pues: Hemos dicho que se debe purificar a quienquiera ascender a lo místico de la divina tiniebla. Y en efecto, no es simplemente, esto es, no sin el misterio de gran significación, el divino Moisés recibió órdenes de purificarse primero, en cuanto al afecto, de todas las inclinaciones terrenas y, en cuanto al intelecto, de todo lo que no es Dios (33). Junto con insistir en la purificación necesaria para ascender a la mística divina, Alberto destaca el "misterio de gran significación". No cabe pasar encima el significativo nexo entre el misterio de la Escritura y el de la Encarnación.

Por cierto, Moisés es calificado de "divino", el primero, quien se someterá a dicha purificación, que consiste en un ordenamiento del afecto-affectus- respecto

(32) 459, 63-73: in EVANGELIO, quod scripsit, quo nos non utimur theologiam, idest sermonem de deo, absolute esse multam propter effectus et figuras, et minimam quantum ad id quod vere in statu viae de deo capere possumus; et specialiter evangelium in quo est doctrina verbi incarnati, dicit esse latum propter multitudinem parabolarum, et magnum propter profunditatem sententiae et mysteriorum, et rursus concisum, idest breve, quantum ad id ad quod est, scilicet ad manifestationem nobis deum, de quo parum nunc capere possumus.

(33) 461, 39-44: ab omnibus emundari, qui ad mysticum divinae caliginis vult ascendere. Etenim non simpliciter, idest non sine magnae significationis mysterio, divinus Moyses praecipitur ipse prius mundari, et quantum ad affectum ab omnibus terrenis affectionibus et quantum ad intellectum ab omnibus quae non sunt deus. 
de las "inclinaciones terrenas"-affectiones-, no de tendencias creaturales, sino "terrenas". Resalta la importancia del afecto (affectus), de las inclinaciones (affectiones); pero mientras el primero articula una realidad positiva, aunque necesitada de purificación, las segundas son vistas negativamente, por cierto, en cuanto son expresión de pecado, como lo insinúa la purificación del intelecto "de todo lo que no es Dios". Cuando Alberto se refiere a la ciencia mística vuelve, una vez más, sobre la purificación en el sentido de remoción, allí donde termina el comentario al capítulo III de la MT: Y por eso esta ciencia es llamada mística en comparación con otras, porque termina en lo oculto, de lo cual no podemos remover algo, ni afirmar algo adecuadamente (34). Alberto da preferencia, aparentemente, a la negación, pese a que termina en lo oculto, "de lo cual no podemos remover nada", lo cual, sin embargo, vale tanto del método como del contenido.

En síntesis, la comprensión albertina de la índole mística, de los misterios y del misterio toma en serio el carácter oculto de la alteridad divina, trascendente, pero rescata su fundamental comunicabilidad. Aunque la negación parece tener preferencia para Alberto, debido a su fidelidad al texto dionisiano, de tal modo que el significado fundamental de misterio se identifica con su índole oculta, sellada, hasta con la oscuridad total, sin embargo se percata una tendencia al movimiento inverso en la argumentación albertina, en la medida en que el autor logra plasmar su enfoque propio. Este se articula desde lo oculto hacia lo manifiesto y como tal repercute en la comprensión del misterio. Para captar los matices de este movimiento cabe ahondar en la comprensión de la alteridad y sus diversas articulaciones, no solo trascendentes, sino también creaturales.

\section{LA ALTERIDAD EN CUANTO MISTERIO Y SUS DIVERSAS ARTICULACIONES}

Pese a que el comentario albertino a la Mystica Theologia en su totalidad resulta una única respuesta a la alteridad del misterio, ella aparece modulada en diversas cristalizaciones por medio del alius, alter, aliud -junto con aliquid- (35), vocablos que cabe analizar en cuanto entretejidos con los ejes precisos de la argumentación central como la otra dimensión del misterio en otros existentes, dualidad misteriosa inclusive-exclusive y distintivo esencial de alteridad en cuanto aliud.

\section{a) La otra dimensión del misterio y los otros existentes}

Al exponer Alberto el problema de la alteridad, recurre a la distinción entre las "teologías afirmativas" y las "negativas", distinción objetiva de la alteridad en cuanto "otra" doctrina, desde la cual pasa a la "subjetiva", es decir, se fija en los sujetos que reciben la "otra doctrina", la enseñanza divina, pues: El método para enseñar la divina (doctrina) consiste en implorar por la oración la verdad de las cosas divinas,

(34) 471, 16. Et propter hoc haec scientia dicitur mystica prae aliis, quia in occulto terminatur, de quod non possumus omnibus remotis aliquid decenter affirmare.

(35) WÖHLER H.U., Alberts des grossen Lehre von den Kontrarietäten, en Albertus Magnus, 157-169. 
que debe ser trasmitida a otros (36). Estos "otros" deben sustentarse en la oración, es decir, la alteridad se abre en su doble referente: Dios y los demás. Pero mientras Dios sigue siendo el Otro, los demás "no son Dios", es decir, el Otro y los otros no se encuentran en un mismo nivel.

El Doctor universalis permite apreciar este desnivel con mayor precisión cuando resalta la simplicidad de Dios, trascendente a todo género y su dualidad de acto y potencia en los demás existentes, aseverando: debe permanecer toda existencia en el acto y no-existencia que son tanto en potencia, porque Dios no se coordina a lo demás existente igual como ocurre en el género de aquellos existentes, y así debe surgir conjuntamente para la imitación de Dios, que permanece por encima de toda substancia y conocimiento, según lo que la mente debiera acatar (37). En estos "otros" existentes, que Alberto distingue aquí, tienen cabida los creados y los recreados a imagen de la gloria y gracia, ya que en ellos la imagen reformada por el hábito de la gloria o la gracia imita en acto a Dios (38).

Esto significa que: referente a lo que el efecto predica de la causa, es necesario que causa y efecto tengan alguna cosa en común; luego decimos que Dios, aunque no tiene nada de las creaturas, ni según el género ni según la especie ni según la analogía, que sean comunes en Él y las creaturas, de todos modos se comunica con ellas según una cierta analogía de imitación, porque ellas lo imitan a Él, en cuanto ellas pueden (39). Pese al abismo óntico que separa al Dios-otro de las creaturas-aliis-, hay "algo"-aliquid-que los une. Pues Alberto, junto con destacar la alteridad de lo creado respecto de Dios -el ipsum-, señala la analogía como una posiblidad de superar el abismo existente por la imitación, ya que los seres humanos están hechos a imagen y semejanza de Dios. De tal modo, imitan a Dios en la medida -secundum quod alia- en que pueden.

Tal posibilidad es comprendida por Alberto, de modo preferente, como conversión a Dios y a ninguna otra cosa fuera de Él, pues: por la conversión de todo a Él, y de nada que existe fuera de Dios, ni en sí mismo ni en otro, porque es convertido a nada fuera de Dios, pero esto es, unido según lo mayor, esto es, según el modo mayor de su unidad, ignorado del todo, esto es, de Dios, por el vacío de todo conocimiento natural, porque a esto no se convierte lo naturalmente conocido, sino a Dios solo, quien no puede ser conocido por ningún conocimiento natural (40). Alberto es insistente respecto de la conversión a Dios, que excluye todo "lo otro", fuera de Él, ni en sí

(36) 455, 88-456, 2: Modus autem docentis divina est, ut per orationem veritatem divinorum impetret, quam tradere aliis debet, quia in omni theologico negotio incipiendum est ab oratione.

(37) 457, 49-54: Et similiter debet relinquere omnia existentia in actu et non-existentia, quae sunt tantum in potentia, quia deus non coordinatur aliis existentibus sicut in genere eorum existens, et sic debet consugere ad imitationem dei, qui est super omnem substantiam et cognitionem, secundum quod mens.

(38) Cf. 457, 54-55: secundum quod mens, in qua est imago reformata per habitum gloriae vel gratiae, actu deum imitatur.

(39) 459, 27-31: quod deus, quamvis non communicet cum creaturis genere vel specie vel analogia, per quam aliquid unum sit in ipso et aliis communicat tamen quadam analogía imitationis, secundum quod alia imitantur ipsum, quantum possunt.

(40) 462, 27-34: per omnimodam conversionem ad ipsum, et nullius praeter deum existens, neque sui ipsius neque alterius, quia ad nihil praeter deum convertitur; autem, idest sed, unitus secundum melius, idest secundum meliorem modum suae unitionis, omnino ignoto, scilicet deo, vacatione omnis cognitionis naturalis, quia ad alia non convertitur naturaliter cognita, sed ad solum deum. 
mismo, ni en otro, Dios es mayor. Y la unión con Él es mayor, ignorando lo demás, es decir, es necesario el "vacío de todo conocimiento natural". No se trata de lo creatural, esto conserva su alteridad congénita, pero hay "algo"no compatible con el ipsum-Dios, quien a su vez posibilita al intelecto humano unirse a Él en cuanto alter creado, marcado por una dualidad misteriosa de inclusión y exclusión.

\section{b) La alteridad, dualidad inclusiva-exclusiva}

Cuando junto con aliis, Alberto usa también alter en la última parte del Capítulo primero, precisa la índole misteriosa de la alteridad en cuanto dualidad. Este hecho llamativo articula una relatividad más concreta de la alteridad, pero también facilita la entrada en una mayor profundidad filosófica, teológica. En efecto, emerge la estructura óntica dual del acto humano, cuando el autor afirma respecto del rapto: el alma no atiende a sus operaciones y la acción de ellas se debilita, porque, como dice el Filósofo, cuando una fuerza se aplica a su acto, el acto de otra fuerza se debilita (41). La dualidad que aquí se patentiza, sin duda, da mejor contorno a la constitución interna del intelecto humano.

Lo mismo sucede cuando el autor resalta un intermedio mediador que permitiría dilucidar el conocimiento de Dios a través de silogismos, pues: Todo lo que es conocido por algo distinto -alter-como por un mediador, es necesario que tenga previamente algún hábito por el cual aquello puede concluirse de sí mismo, así corresponde en los silogismos, o al menos hay alguna vía a través de la cual se puede llegar a aquello, tal como por la luz infusa de la fe llegamos a los artículos de la fe. Pero el no-ver y no-conocer no tiene tal algo: por eso, por el no-ver y noconocer no podemos conocer a Dios (42). Según este contraargumento, la teología negativa, al carecer de una alteridad de contornos precisos, parece imposibilitar el conocimiento de Dios. Pero, de hecho, Dios se revela aquí en su verdadera alteridad para el intelecto humano en cuanto misterio.

Esto puede apreciarse, cuando el autor hace entrar en juego la idea de causalidad, diciendo: La causa de toda negación es alguna oposición o diversificación; por eso es reductible a una cierta comunidad; Dios, sin embargo, no tiene nada en común con las otras realidades -aliis-, que está compuesto y tiene algunas diferencias constituyentes; de ahí que parece que no puede negarse algo-aliquid-de Él, ni las realidades supremas ni las ínfimas (43). Resalta, con fuerza, la trascendencia

(41) 462, 90- 463, 2: quia anima non attendit operationibus ipsarum et earum actio debilitatur, quia quando una virtus intenditur in suo actu, actus alterius debilitatur, sicut dicit PHILOSOPHUS

(42) 466, 27-34: Omne enim per quod cognoscitur alterum sicut per medium, oportet, quod habeat aliquam habitudinem per quam illud possit concludi ex ipso sicut est in syllogismis, vel ad minus quod habeat aliquam viam per quam possit deveniri in illud, sicut per lumen fidei infusum devenimus in articulos; sed non-videre et non-cognoscere non habet aliquid talium; 466, 41-47: aut non-videre istud per quod deus videtur, ponit aliquid aut nihil, si nihil cum ex puris negationibus non possit aliquid concludi, quia non est aliquis syllogismus ex omnibus negativis, ergo per hoc non venietur in aliquam cognitionem; si autem ponit aliquid et negat aliquid, aut est principium cognitionis divinae seu via quaedam per hoc quod negat.

(43) 467, 70-76: omnis negationis causa est aliqua oppositio vel disparatio, haec autem reducuntur ad aliquam communitatem; deus autem nihil habet commune cum aliis, quia esset compositus et haberet aliquas differentias constituentes, ergo videtur quod non possit aliquid de ipso negari, neque suprema neque infima. 
de Dios en cuanto alteridad respecto de las creaturas, con las cuales el sujeto-Dios no tiene nada en comun. Si, pese a todo, le es posible a la creatura acercarse a Dios, debe haber una solución al problema, que el autor resalta así: porque, de este modo, que Dios no tenga nada en común con ellas, hay entre Él y ellas una comunidad de imitación (44). Sin duda, al destacar la argumentación de Alberto una posibilidad de unirse el intelecto humano por imitación con el Dios-Sujeto-Otro, enfatiza, más allá del enfoque filosófico metafísico un proceder teológico práctico del misterio en relación con su origen trinitario.

\section{c) El origen trinitario de la alteridad}

Desde la imitación señalada cabe fijarse cómo Alberto abordará el origen de las personas divinas, que acontece en el corazón, en cuanto permanecen en una esencia, según que una y otra de las personas permanece en sí, según que el Hijo está en el Padre y el Padre en el Hijo, al modo como una persona procede de otra por la propagación coeterna -coaeterna pullulatione-, porque la generación del Hijo no precede a la espiración del Espíritu, ni la espiración del Espíritu precede a la generación del Hijo, porque no hay un paso de las potencias al acto (45). La alteridad surge aquí desde su profundidad mayor, el misterio por excelencia, donde una persona divina existe en la otra -alia-, a partir de su procedencia eterna, que no implica precedencia ni paso de las potencia al acto, sino compenetración.

Sin duda, es difícil comprender tal compenetración de una persona por la otra a nivel científico. Si, además, cabe compaginarla con la Encarnación, la cuestión se pone más difícil todavía, ya que a nivel científico se concluye o desarrolla a partir de principios diversos, aquello que no trata de la misma doctrina, hasta tal punto que una manera de conclusión está demostrada por los principios de otros y otras, que pertenecen a diversas ciencias... Pero la encarnación del Verbo y la distinción de las personas no es determinada a partir de los mismos principios, porque la distinción de las personas está determinada por relaciones eternas, la encarnación, sin embargo, por operaciones temporales; por eso, parece que estos no pertenecen a la misma doctrina (46). Alberto esclarece este argumento que contrapone las procesiones eternas en Dios con aspectos esenciales del misterio de la Encarnación como perteneciente a una sola doctrina, la teología negativa, es decir, mística,

El autor elabora su aclaración a partir de diversos principios, que cuestionan la mismidad de la doctrina, pues: como la Encarnación del Verbo conviene singularmente al Hijo, conviene que ella sea determinada con las otras propiedades de las

(44) 467, 89-92: ad tertium iam patet solutio per ea quae PRIUS dicta sunt, quia quamvis non sit comunitas dei ad alia qualis aliorum ad invicen, est tamen communitas imitationis.

(45) 470, 8 -12: a mansione in ipso, scilicet corde, inquantum manent in una essentia, et in seipsis, secundum quod unaquaeque personarrum manet in se, et in se invicem, secundum quod filius est in patre et patre in filio, quamvis una persona procedat ab alia coeterna pullulatione, quia generatio filium non praecedit nec spiratio spiritum sanctum, quia non est exitus de potentia ad actum.

(46) 470, 22-33: Quae enim diversis principiis concluduntur vel determinantur, non sunt eiusdem doctrinae, ita quod si eadem etiam conclusio per alia et alia principia demostretur, pertinet ad diversas scientias... sed incarnatio verbi et distinctio personarum non determinantur eisdem principiis, quia distinctio personarum determinatur per relationes aeternas, incarnatio autem per operationes quasdam temporales; ergo videtur, quod non pertineante ad eandem doctrinam. 
personas. Ella, en efecto, es estudiada con ayuda de principios comunes, es decir, por las relaciones eternas que distinguen a las personas; el Hijo, pues por la filiación es desde la eternidad Hijo del Padre y a partir del tiempo Hijo de la madre, y por la misma personalidad es Dios y hombre, y si agregamos también los principios propios para determinar la encarnación, esto no es inconveniente, porque lo que está determinado en la misma ciencia, bien puede diferir en los principios propios (47). La alteridad así queda salvaguardada, por la diferencia, que el autor resalta tanto a nivel de contenido como de principios metódicos.

Más allá de las diferencias de principios entra en cuestión otro factor, lo sensible, que se distingue de lo inteligible, como Alberto recuerda, evocando Dionisio, pues: de qué modo Dios se llama bueno, y lo demás que pertenece a las denominaciones inteligibles de Dios, a saber, aquellas que, así, en el intelecto suyo no expresan algo sensible (48). En efecto, la distinción entre lo sensible e inteligible compromete, metódicamente, la alteridad, al mismo tiempo que se ahonda la teología símbólica a partir del significado metafórico, pues son determinadas las denominaciones de Dios, que son transmutadas en un sentido metafórico según lo sensible en Dios, así que son formas retenidas para significar lo divino, aquellas figuras, en cuanto se entienden así por la forma y figura las mismas cosas en cuanto a la realidad, pero desde el punto de vista interior y el punto de vista exterior no tienen el sentido de forma substancial, y paralelamente a otros títulos que son dichos de Dios en un sentido simbólico (49). Alberto visualiza aquí, sin duda, una expresión teológica científica.

Esto lo refuerza el autor, cuando constata: En toda predicación, pues, debe aceptar lo que está sujeto y lo que está sujeto que sea en el mismo y tenga alguna composición con el mismo y debe ser otra vez aceptarse la proporción de la subjetibilidad en el sujeto y de la predicabilidad en lo predicado, y por eso es de modo inverso y propio no puede de Dios formarse una proposición, como prueba el Comentarista en el XI de Metafísica, pero usamos hablando a partir de él palabras acomodadas y significamos esto en sujeto y predicado y no es alguna diferencia de cosa, sino más bien en el modo de inteligencia, que se funda en el aspecto hacia fuera (50). La alteridad divina excede la relación sujeto y objeto, por eso usamos

(47) 470, 33-43: quod cum incarnatio verbi conveniat singulariter filio, convenienter determinatur cum aliis propriis personarum; determinatur enim per eadem principia in communi, quia per relationes aeternas et distinguentes personas; filius enim eadem filiatione est ab aeterno filius patris et ex tempore filius matris et eadem personalitate est hic deus et hic homo, et si addantur quaedam etiam principia propria ad determinationem incarnationis, non est inconveniens, quia quae determinantur in eadem scientia, bene possunt differre in principiis propriis.

(48) 470, 45-47: quomodo deus dicatur bonus, et cetera alia quae pertinent ad intelligibiles deinominationes, quae scilicet in intellectu suo non exprimunt aliquod sensibile.

(49) 470, 49-54: determinatae sunt dei nominationes, quae transumuntur a sensibilibus in deum, sicut quae sunt divinae formae, quae figurae; et sumitur pro eodem hic forma et figura re, sed differunt ratione per interius et exterius; non enim sumitur pro forma substantiali; et similiter de omnibus aliis quae de deo symbolice dicuntur.

(50) 474, 14-23: sed in deo nulla est compositio et ideo neque aliquid in alio vel sub alio, et ideo ipsa res divina excedit omnem proportionem subicibilitatis et praedicabilitatis, et propter hoc vere et proprie non potest de deo formari propositio, sicut probat COMMENTATOR in XI METTAPHYSICAE, sed utimur loquentes de ipso accomodatis verbis et significamus idem in subiecto et praedicato, et non est aliqua differentia rei, sed tantum in modo intelligendi, qui fundatur in respectu ad extra. 
palabras acomodadas, es decir, hay una forma de inteligencia que excede toda proporcionalidad.

Lo mismo resalta Alberto en relación con la doble fantasía que tampoco alcanza a Dios, pues: el Comentarista distingue dos especies de fantasías, de las cuales ninguna se encuentra en Dios. La primera, si bien se sitúa en la naturaleza sensible, no es sentido por Él. Ella nace en el órgano de los poderes sensibles y se llama en el sentido propiamente tal la imagen que está impresa. La otra es la que, consecuentemente con la primera, está formada por la imagen sensible y es esta fantasía que propiamente se suele llamar el sentido interior (51). Sin duda, emerge aquí la complejidad del intelecto humano y su interrelación con la fantasía que es propia de la mente humana, pero que no poseen ni los ángeles ni Dios.

En sintesis: cabe apreciar un desarrollo progresivo de la comprensión multifacética de la alteridad, que emerge del uso consecuente de alter, alius, ligados al aliquid. Junto con precisar el alcance de la alteridad, se gesta una confluencia entre alteridad y misterio que semejante a opuestos se entretejerán en una respuesta al problema planteado, cuando Alberto reconduce el misterio de la alteridad a su origen trinitario fundante.

\section{LA RECONDUCCIÓN DEL MISTERIO DE LA ALTERIDAD A SU ORIGEN FUNDANTE}

Si bien Alberto no se aparta del texto dionisiano, hace confluir el misterio y la alteridad al interior de la scientia mystica, apoyado en el uso de alius-alter-aliud y concretado en cuanto nexo - ad- entre lo de Dios y lo del hombre, nexo por cierto desproporcionado con respecto a la recepción del sujeto (52), pero que se encamina hacia el ad-aliquid trinitario desde donde se proyecta como exceso en la distinción entre ratio e intellectus. La reconducción al origen fundante de tal Misterio de la Alteridad se produce gracias a aquella tensión entre prius y posterius (53), que recibe su significado teológico antropológico en la fórmula speculum aeternitatis.

\section{a) La recepción misteriosa de la alteridad de parte del sujeto}

Cuando Alberto explicita el método científico, tanto a nivel racional natural cuanto a la ciencia mística, se refiere a la recepción de dicho misterio de parte del

(51) 474, 58-64: Prima est, quae ex sensibili natura primero in instrumento sensuum nascitur et imago in sensibus expressa proprie vocatur; altera vero est ipsa quae consequenti ordini ex praedicta imagine formatur et est ipsa phantasia quae proprie sensus interior consuevit vocari.

(52) Cf. 454, 77-455, 3: Dicendum, quod negativae theologiae, sicut in TERTIO CAPITULO dicitur, incipiunt a manifestis nobis sensibilibus, negando ea a deo, et sic procedentes removendo omnia ab ipso relinquunt intellectum nostrum in quodam confuso, a quo negantur omnia quae novit, et de quo non potest affirmare, quid sit. Affirmativae autem theologiae producunt nobis occultum divinitatis in manifestum, secundum quod significantur ab eminentiae causa procedere ea quae sunt manifesta nobis...

(53) ANZULEWICZ H./RIGO C., "Reductio ad esse divinum". Zur Vollendung des Menschen nach Albertus Magnus, en ARSTEN J.A./PICKAVÉ (eds.), Ende und Vollendung. Eschattologische Perspektiven im Mittelalter /(Miscellanea Mediaevalia, 29) Berlin-New York 2002, 388-416. 
sujeto, de la siguiente manera: ...la ciencia, que procede de los principios de la razón pone al descubierto aquello a-ad-lo cual conduce. Pero la presente doctrina no procede de tales principios, sino más potentemente de una cierta luz divina, donde no hay enunciado, por el cual algo es afirmado, y sí más bien cosas que convencen al intelecto, para que, encima de todo, se adhiera a ella. Por eso, eleva al intelecto a-ad-aquello que le excede a él mismo, razón por la cual el intelecto permanece estable en aquello que no es conocido de modo determinante. Esta luz es proporcional a la luz, la cual asegura a la visión corporal la capacidad de ver-ad videndum-, pero sin facilitar el conocimiento de una cosa determinada, ya que no posee determinación específica propia (54). Aquí emerge un triple ad, que se proyecta desde $-a b-\ldots a-a d-$, el intelecto "es conducido", "es elevado", pero, paradójicamente, permanece estable, al excederse a sí mismo. Entra en juego una luz potente divina, pero proporcional a la natural, en el sentido que asegura la capacidad para ver. Sin embargo, resalta la diferencia entre los procedimientos metódicos, en cuanto el natural aporta lo determinante, el iluminado por la luz divina no posee "determinación específica propia", de tal modo que el intelecto "se adhiere a ella encima de todo".

El método, que procede según los principios de la razón llega a resultados determinados, a-ad- los que pretende conducir; el "místico", por su parte, no tiene un ad inmanente, sino depende de una "luz divina"-lumen-, que está encima de todo. Ella es luz, "proporcional" a la luz natural, pero desemejante en cuanto al "conocimiento determinado", siendo así in-determinado. Como tal, nuestro intelecto -intellectus noster- es traído -traho en pasivo-, lo cual significa para él, a la vez, subsistencia y participación. Subsistencia, porque es el mismo que recibe la acción divina; participación, porque da un paso de lo oculto a lo manifiesto, a modo del engendramiento de la Palabra (55). Esto lo explicita Alberto cuando asevera: ... según el orden natural de aquella doctrina va desde lo oculto a-ad-lo manifiesto, porque lo propio es anterior a lo que es apropiado; la apropiación, entonces, no puede hacerse sino por la referencia a lo propio, así como no puede saberse por qué se dice que Dios está durmiendo, si no se sabe primero, de qué modo esto es desemejante; propias también son las cosas ocultas, apropiadas, sin embargo, manifiestas, y, por eso, se da el proceso desde lo oculto a-ad-lo manifiesto (56). El

(54) 455, 12-455, 24: quod scientia, quae procedit ex principiis rationis, ponit in aperto ea ad quae ducit. Huiusmodi autem doctrina non procedit ex talis principiis, sed potius ex quodam lumine divino, quod non est enuntiatio, per quam aliquid affirmetur, sed res quaedam convincens intellectum ut sibi super omnia adhaereatur. Et ideo elevat intellectum ad id quod excedit ipsum, propter quod remanet intellectus in quodam non determinante noto. Et hoc lumen proportionatur lumini, quo corporalis visus confortatur ad videndum, quod tamen non facit alicuius visibilis determinantam cognitionem, cum nullus species propria sit.

(55) 455, 33-37: quia per hoc quod affirmatur aliquid de eis in illa doctrina, ut quod pater generat vel quod sunt tres personae, trahitur intellectus noster ex occulto deitatis ad res manifestas, in quibus aliquod indicium invenitur, relictum in eis ex causa prima. Haec autem scientia dicitur mystica quantum ad modum.

(56) 455, 57-64: tamen secundum naturalem ordinem illius doctrinae itur ab occultis ad manifesta, quia prius est proprium quam appropriatum; appropriatio enim non potest fieri nisi per proportionem ad propria, sicut non potest sciri, quare deus dicatur dormiens, nisi prius sciatur, quomodo est dissimulans; propria autem occulta sunt, appropriata autem manifesta, et ideo etiam ibi est processus ab occultis ad manifesta. 
paso de lo oculto a lo manifiesto, sin duda, se refiere a las apropriaciones de las relaciones trinitarias y como tal remontan a lo propio en Dios, que queda oculto.

Pero para conocer esta profundidad "propia de Dios", cabe unirse a ella. De ahí que vale: El método que trata la realidad divina es doble, de los cuales el primero consiste en el conocimiento, el segundo en la unión con-ad-Dios, porque así se dice en la Caelesti Hierachia, "la jerarquía es ciencia y acción y se orienta hacia Dios, en cuanto es posible, semejanza y unidad". Y por eso, la primera parte se divide en dos; en la primera expone el método como debe conocerse la divina, en la segunda el método de unión con-ad-Dios (57). Resulta importante la referencia a la capacidad del sujeto cognoscente a la vez que la insistencia en la unión con Dios-ad-. Pero esto implica que el - $a d$ - orientado hasta el momento, de modo vertical, se extienda a nivel horizontal a través de la relación maestro-discípulo, que Alberto precisa con ahínco, por un viraje significativo, cuando se preocupa de los presupuestos subjetivos de la recepción adecuada de la alteridad y de su misterio.

Esto trasunta en la insistencia del autor respecto de la necesidad de la oración de parte del sujeto, interrelacionada con la verdad, pues:... la doctrina debe proceder del maestro al discípulo; pero la verdad implorada por la oración puede igualmente darse para-ad-el maestro y el discípulo (58). Pero se trata aquí del segundo contraargumento, donde el autor evoca la importancia de la relación maestro-discípulo para agregar:... la verdad, que está encima de nuestra ciencia, no puede aceptarse si su benignidad no es inclinada a-ad-lo que se infunde en nosotros; como, por eso, tal es la verdad, que se busca, y la benignidad divina no es inclinada sino por la oración, se ve que la oración debe ser el método del que enseña según esta doctrina (59). Aparece aquí la importancia de un movimiento, exclusivamente, descendente, lo cual no le basta a Alberto. ¿Por qué no?

La oración es importante para el conocimiento de la verdad en cuanto interrelacionada con la benignidad. Pero el autor insiste:... como la verdad divina supera nuestra razón, no podemos hacerla manifiesta desde nosotros mismos, a menos que ella misma se digne infundirse (en nosotros), pues es el maestro interior, sin el cual el maestro exterior trabaja en vano, como dice Agustín. Pero la doctrina exterior no es superflua, porque es el instrumento, como dice el Salmo 44, 2: "La lengua mía es como pluma de ágil escriba", que en el alma del oyente manifiesta por oraciones significativas lo verdadero o falso. Y porque, por eso, es necesaria, a partir de la dualidad de maestros, cada una de las dos cosas: el enunciado, que observa el

(57) 455, 79-84: Modus autem tractantis divina est duplex, quorum prius consistit in cognitione, secundum in unitione ad deum, quia, sicut in CAELESTI HIERARCHIA dictum est, "hierarchia est scientia et actio et ad deum, quantum possibile est, similitudo et unitas". Et ideo prima pars dividitur in duas; in prima ponit modum cognoscendi divina, in secunda modum unitionis ad deum.

(58) 456, 16-18: doctrina debet procedere a magistro in discipulum, sed veritas per orationem impetrata aequaliter potest se habere ad magistrum et discípulum, quia non respicit ordinem magisterii, sed magis ordinem sanctitatis; ergo videtur, quod non sit modus docentis oratione procedere.

(59) 456, 18-24: veritas, quae est supra scientiam nostram, non potest accipi, nisi sua benignitas inclinetur ad hoc quod infundat se nobis; cum igitur talis sit veritas, quae hic quaeritur, et divina benignitas non inclinetur nisi oratione, videtur, quod oratio debeat esse modus docentis secundum hanc doctrinam. 
orden del maestro al-ad-discípulo, y la súplica (60). Junto con señalar la fuente agustiniana y subrayar la importancia del maestro interior en la infusión de la verdad, Alberto insiste en la dimensión exterior propia de la verdad que como tal trasunta en la relación intersubjetiva de maestro y discípulo, del yo y el otro.

Desde esta perspectiva intersubjetiva interior/exterior y horizontal la argumentación albertina toma vuelo ascendente a través de un nuevo contraargumento, pues:... hay que decir que Dios es llamado en Sí el superesplendoroso, pero oculto para nosotros, porque las realidades, que por naturaleza son más manifiestas se comportan respecto de-ad-nuestro intelecto como la luz del sol para el ojo de la lechuza (61). Esta verdad motiva a Alberto a insistir, aseverando: hay que decir que en las cosas inferiores, ciertamente simples desde el punto de vista del modo de conocimiento (que hay en nosotros), son en su ser realmente compuesto y dependiente de-ad- la materia... Pero Dios es simple desde el punto de vista de su ser, porque no depende de algo, porque en Sí es perfecto y no se mueve ni por Sí mismo ni por accidente (62). Resalta aquí la simplicidad de Dios con que Alberto pone fin a la discusión en torno a la necesidad de la oración de parte del sujeto para conocer el misterio (63) y aborda el contenido de dicha oración.

El contenido de la oración, trasmitida por Dionisio, se proyecta en su dimensión trinitaria, pues reza así: Trinidad: suprasubstancial, esto es, que has hecho que todo es, y supradivina -superdea, en cuanto provee lo que-ad-está existiendo ya, y suprabuena -superbona-, en cuanto dirige las cosas a su fin, "inspectora de la sabiduría divina" -inspectrix sapientiae divinae-, esto es, que es de Dios, porque Él mismo solo es perfecto contemplador de Sí mismo; y por eso, es llamado "inspectrix", como está inspeccionando intimamente. Y dice "de los cristianos" -Cristianorum- para-addiferenciar la ciencia divina de la que también tienen los filósofos de Dios, que está mezclada con muchísimos errores a causa de la debilidad de la razón humana (64).

(60) 456, 28-38: quia cum divina veritas superet nostram rationem, nos ex nobis eam manifestare non possumus, nisi ipsa se dignetur infundere; ipsa enim est magisteri interior, sine quo frustra laborat magister exterior, ut dicit AUGUSTINUS. Nec tamen superflua est doctrina exterior, quae est sicut instrumentum, sicut dicitur in PSALMO (XLIV, 2): "Lingua mea calamus scribae", quae se exserit in animam auditoris per orationes significantes verum et falsum. Et ideo propter utrumque magistratrum utrumque necessarium est, et enuntiatio, quae respicit ordinem magistri ad discipulum, et deprecatio.

(61) 456, 56-61: Dicendum ad primum, quod dicitur deus supersplendens in se, occultus autem nobis, quia manifestissima naturae se habent ad intellectum nostrum sicut oculus noctuae ad lumen solis.Vel dicendum, quod est occultus secundum se in altitudinem suae naturae, supersplendens autem secundum quod se nobis immittit.

(62) 456, 62-71: quod in inferioribus sunt quaedam simplicia secundum modum intelligendi quae secundum esse composita sunt et dependent ad materiam, sicut essentiae rerum naturalium et haec eadem per se immobilia sunt et indestructibilia, sed per accidens corrumpuntur corruptis his in quibus sunt. Sed Deus et secundum intellectum simplex est et secundum esse absolutum, non dependens ad aliquid, quia in se perfectum est et non movetur neque per se neque per accidens.

(63) SICOULY P.C., Gebet als instrumentum theologiae. Zu einer Aussage Alberts des Grossen in seinem Kommentar zu Ps. Dionysius De divinis nominibus, en SENNER W., ANZULEWICZ H., (eds.), Albertus Magnus. Zum Gedenken nach 800 Jahren: Neue Zugänge, Aspekte und Perspektiven, Berlin 2001, 619-631.

(64) 457, 1-12: O trinitas supersubstantialis, id est quae omnia esse facis, et superdea, quantum ad hoc quod iam existentibus providet, et superbona, inquantum dirigit ea in finem, inspectrix sapientiae divinae, idest quae de deo est, Christianorum, idest a Christianis habita, quia ipse solus perfectus sui contemplator est; et ideo dicit "inspectrix", quasi intime spectans. Et dicit "Christianorum" ad differentiam scientiae divinae, quam de deo philosophi etiam habuerunt, quae plurimis erroribus mixta fuit propter imbecillitatem rationis humanae. 
No cabe duda de que la Trinidad misma dirige las cosas a- $a d$-su fin, por lo cual el $a d$ articula su dinamismo teleológico, decisivo para la argumentación propia de Alberto. Además, el autor subraya así la diferencia de la ciencia de los cristianos en cuanto supradivina, con respecto a otras y se caracteriza por ser la "inspectora de la sabiduría divina".

De ahí que el autor pide que la Trinidad nos oriente hacia el vértice de los misterios, pues: dirígenos al-ad-sumo vértice de las escrituras místicas ... asimismo nuestra vista está oscurecida por una luz más fuerte, que no es apta para-adsoportar un esplendor muy vivo (65). Pese a que el misterio de la alteridad recibe su máxima expresión, Alberto agrega una significativa acotación, pues el esplendor de la ciencia mística: sobrellena nuestras mentes y la de los ángeles, que no tienen ojos corpóreos, por las claridades más admirables de la iluminaciones divinas, por un don sublime, del todo impalpable, porque no es conocido por el sentido exterior, ni visible en cuanto a-ad- la vista interior (66). Junto con destacar este "don sublime", Alberto objeta, defendiendo a Dionisio:... hay que decir que en otros libros, que se ha hecho de Dios, Dionisio expone las realidades divinas en lo que se hace manifiesto para-ad-nosotros, como está dicho; en este, sin embargo, es necesario para nosotros ir a Dios y unirnos con Él. Y esto es toda la perfección divina de la ciencia; donde se requiere de una perfección mayor en el oyente (67). ¿En qué consistirá esta perfección mayor, si no en una recepción más adecuada del "don sublime"? De todos modos, se trata de una capacitación mayor por medio de la unión con Dios.

En efecto, el oyente debe unirse a Dios en un continuo ir hacia Él, lo cual requiere de aquel que estudia esta "ciencia mística", un cuidado especial, que lo contrapone al ignorante, al cual no debe entregarse dicha ciencia. De hecho, "aquellos ignorantes... son desemejantes en cuanto a su afecto y su intelecto a las formas de quienes reciben la ciencia, aunque en nada creen que exista la esencia suprasubstancialmente, esto es, lo que no tenga una proporcionalidad relativa a-adellos. De ahí que los filósofos dicen que el Primer Motor es proporcional a lo movido por el primer motor (68). Lo que importa es la actitud sujetiva de parte del oyente, pero también resalta el "primer motor" y la posibilidad de ser alcanzado por la razón. Esta afirmación sufre un cambio significativo cuando entra en juego la vivacidad de la fe, pues: ...hay que decir que lo divino no se aprehende por principios de la razón, sino por "la compasión hacia-ad-ello", como de Hierotheo dice

(65) 457, 12 dirige nos ad summum verticem mysticorum eloquiorum, 457, 20: sed ex nimio ipsius splendore obtenebratur noster oculus, quia impotens est ad tantum splendorem,

(66) 457, 31-35: Et ideo subdit: et superimpletentem mentes nostras et angelorum non habentes oculos corporeos superpulchris claritatibus divinarum illuminationum in summo illo omnino impalpabi$l i$, quia non cognoscitur sensu exteriori, et invisibili quantum ad visum interiorem.

(67) 458, 10-15: quod in aliis libris, quos de deo fecit, afferuntur divina ad nos in manifestis, ut DICTUM EST; in hoc autem oportet nos ire in deum et unirri sibi. Et ideo haec est tota perfectio divinae scientiae; unde requiritus maior perfectio in auditore.

(68) 458, 33-40: Dicit ergo primo, quod hic cavere debet, ne aliquis indoctus in divina doctrina audita ista mystica. Dicit enim illos indoctos, qui, cum sint informati et secundum affectum et secundum intellectum exitentibus, a quibus scientiam accipimus, nihil credunt esse super entia supersubstantialiter, idest sine proportione ad ipsa. Unde etiam PHILOSOPHI dicunt, quod motor primus est proportionatus mobili primo. 
Dionisio, que aprendió lo divino "sufriendo lo divino" (69). Llama la atención la insistencia en la "compasión hacia ..." y el hecho de que "lo divino hay que sufrir"; es decir, Alberto va afinando la índole pasiva de la mente humana en un sentido filosófico por la dimensión más bien teológica de "compasión" y "sufrimiento", lo cual es constitutivo, también filosóficamente, de toda alteridad en la ipseidad (70).

El autor compromete, entonces, la experiencia del sujeto con la acción de Dios, señalando, de tal modo, al quehacer teológico-negotium-, una posibilidad, aunque breve, de alcanzar aquella profundidad de los misterios, que la mera razón humana no puede alcanzar, por medio del sermón de Dios, el Misterio del Verbo Encarnado (71). Resalta aquí la diferencia del Evangelio con respecto a cualquier ciencia, debido a la presencia del misterio del Verbo encarnado, que requiere una peculiar atención de parte de la racionalidad humana para hacerse cada vez más apta, a la vez que esta misma capacidad está, continuamente, desafiada por el exceso de la luz divina, que al desbordar al hombre capax dei lo eleva hacia la unión, es decir, confluyen el misterio y la alteridad en un significativo exceso entre el momento presente y la eternidad.

\section{b) El exceso del misterio de la alteridad}

Alberto deja constancia de que no hay coincidencia entre el misterio y la alteridad, allí donde ambos confluyen, sino exceso. Pues ambas realidades se trascienden en un espacio común, nunca plenamente delimitado, sino borroso-confuso. El origen de tal confusión borrosa se encuentra en el estado defectuoso de nuestra capacidad intelectiva, pero sobre todo en el mismo "rayo de las tinieblas divinas", pues: Timoteo se eleva hacia-ad- el rayo de las tinieblas divinas, esto es, saliendo de sí mismo, excede a sí mismo irresistiblemente, sin retenerse en el campo que rigen los principios de la razón (72). El sujeto de la ciencia mística es elevado hacia "el rayo de las tinieblas divinas", lo cual significa salirse de sí mismo y excederse a sí mismo. Esto parece una imposibilidad, objeta Alberto, ya que: Nada excede de sí mismo, y así, como se exhorta a-ad-ello, parece exhortar a lo imposible (73).

Sin embargo, tal exceso resulta posible cuando se lo comprende no en clave de ser, sino de virtud, pues por medio de la virtud el sujeto puede resultar extendido encima de sí mismo, en cuanto se vuelca sobre un objeto, que es más elevado que él

(69) 458, 54-57: quod divina non accipiuntur per principia rationis, sed quodam experimento per "compassionem ad ipsa", sicut de HIEROTHEO dicit DIONYSIUS, quod didicit divina "patiendo divina".

(70) Cf. KÜHN R., Selbstvergessen und Passibilität. Absoluter Idealismus und radikale Phänomenologie, Phänomenologische Forschungen, Hamburg 2003, 189-211; RICOEUR P., Sí mismo como otro, Madrid 1996, $415 \mathrm{pp}$.

(71) 459, 63-73: in EVANGELIO, quod scripsit, quo nos non utimur theologiam, idest sermonem de deo, absolute esse multam propter effectus et figuras, et minimam quantum ad id quod vere in statu viae de deo capere possumus; et specialiter evangelium in quo est doctrina verbi incarnati, dicit esse latum propter multitudinem parabolarum, et magnum propter profunditatem sententiae et mysteriorum, et rursus concisum, idest breve, quantum ad id ad quod est, scilicet ad manifestationem nobis deum, de quo parum nunc capere possumus.

(72) 457, 58-61: sic sursum agatur ad radium divinarum tenebrarum, cuncta auferens, idest deserens, excediendo seipsum irretentibiliter, quasi non retenendo se intra principia rationis.

(73) 458, 8-9 nihil excedit seipsum, et ita, cum ad hoc hortatur eum, videtur hortari ad impossibile. 
mismo. A este traspaso de un estado a otro superior invita el autor (74), es decir, a introducirse a la "tiniebla espesa", donde Dios está, verdaderamente, en cuanto "está encima de todo". Pues ...verdaderarmente en cuanto a-ad-la verdad del objeto, que aparece solo en lo que trasciende tendiendo a Dios, esto es, trascenderán lo inmundo, esto es, las creaturas materiales y puras, esto es, inmateriales, y que gravitan sobre todo, esto es, vienen encima de todo, el ascenso de todas extremidades del santuario, esto es, de los ángeles, y dice extremidades aquello en que la naturaleza inferior toca la superior, en lo más íntimo toca ella la naturaleza inferior en lo sumo suyo.Y porque ella está encima de toda naturaleza debe trascender a su modo las extremidades para llegar a-ad-Él (75). Se visibiliza aquí el exceso en cuanto llegada a Dios, que implica un traspaso, a modo de exceso, que se extiende más allá de las cosas materiales e inmateriales, los ángeles, cuya dinámica de fondo es un continuo trascender hacia Dios.

Este traspaso, que al sujeto hace exceder, más y más, parece requerir de un intermedio, observa Alberto, contraargumentando, lo cual podrán ser, en primer lugar, los ángeles en cuanto "intelectos inmateriales", pues: ... es necesario que las almas se unan primero a sí mismas y después por el intelecto inmaterial y simple llegan a-ad-la unión divina; por eso, parece, que no debemos dejar de lado a los ángeles, que son intelectos inmateriales, sino unirnos a ellos en cuanto podemos, para que de tal manera lleguemos a Dios (76). Además, las luces divinas nos son dadas, para fortalecer el intelecto en su conocimiento de Dios; pero no debemos dejar de lado llevar al fin aquello que ayuda al ascenso hasta el fin; por eso, parece, que no debemos dejar de lado las luces divinas para-ad-conocer a Dios, sino fuertemente adherir a ellas (77). Mientras estos contraargumentos destacan la unión divina y su contemplación, insisten en unirse a los ángeles y adherirse a las luces divinas.

Lo que parece evidente Alberto lo rechaza, solucionándolo de modo distinto, pues.... hay que decir que la contemplación de Dios debe ser considerada doblemente: o en cuanto a-ad-aquello en que contemplamos a Dios, o en cuanto al principio de la contemplación, y así dice Dionisio en la Caelesti Hierarchia, que no

(74) 458, 23-26: ad quartum dicendum, quod nihil excedit se secundum esse, sed virtus sua potest extendi supra ipsum, inquantum fertur in obiectum, quod est elevatum ab ipso, et ad hoc eum hortatur.

(75) 460, 7-23: neque intellectum, idest intellectus comprehensionem passive, propter hoc quod ipsa causa est superposita omnibus quantum ad altitudinem suae naturae, supersubstantialiter quantum ad modum essendi, et apparet non -velate quantum ad modum accipiendi ipsum, et vere quantum ad veritatem obiecti, quod videtur solum his qui tendentes in deum transeunt, idest trascendunt, immunda, idest materiales creaturas, et mundas, idest immateriales, et qui superveniunt omnem, idest veniunt super omnem, ascensum omnium sanctarum extremitatem, idest angelicarum, et dicuntur extremitates illud in quo inferior natura attingit superiorem, in cuius infimo attingit eam inferior natura in summo sui. Et quia ipse est super omnem naturam, oportet omnes huiusmodo extremitates transcendere ut veniatur ad ipsum.

(76) 460, 48-53: quod oportet animas uniri in seipsum primo et postmodum per immaterialem et simplicem intellectum pervenire ad unitionem divinam; ergo videtur, quod non debeamus relinquere angelos, qui sunt intellectus immateriales, sed uniri nos sibi, quantum possumus, ad hoc, ut veniamus in deum.

(77) 460, 54-59: divina lumina dantur nobis, ut confortent intellectum ad cognoscendum deum; sed non est relinquendum eunti in finem illud quod iuvat ascensum in finem; ergo videtur, quod non debeamus relinquere divina lumina ad cognoscendum deum, sed fortiter ei inhaerere. 
podemos ver el rayo divino en esta vida, sino bajo el velo de los signos y efectos, porque "ahora vemos en espejo y enigma"; o en cuanto al-ad-fin de la contemplación, o sea en cuanto a lo que buscamos por la contemplación, y esto es Dios mismo no-velado, a lo cual llegamos en lo último nuestro, en lo cual tocamos las naturalezas intelectuales; se frustra pues la búsqueda racional, si no llega a-ad- la unión intelectiva (78). Alberto destaca que pese a la única posibilidad de ver bajo el velo de los signos y efectos, es decir, en espejo y enigma, pero a Dios mismo, no por medio de instancias intermedias, sino escatológicamente, se llega a lo último.

Pero la unión intelectiva es necesaria para la realización del intelecto humano... que es traspasar algo por la contemplación doblemente: o en cuanto a-ad- la fuerza contemplativa, y así no podemos ni trascender ni igualarnos a los ángeles en esta vida, aunque somos elevados por la luz divina encima de la facultad de nuestra naturaleza, o en cuanto al-ad-objeto de la contemplación, y así, porque lo que buscamos está encima de todo, traspasamos también los ángeles contemplando, como en el Cántico se dice: "apenas los había pasado, encontré a quien ama mi alma" (79). Hay un doble traspaso o en cuanto a la fuerza contemplativa o al objeto de la contemplación, lo cual significa un traspasar a los ángeles, como el autor fundamenta, básandose en una cita del Cantar de los Cantares. Es Dios mismo, en busca del cual va el intelecto humano, el amado por encima de todo, es decir, el exceso del intelecto desemboca en el amor, quien produce el encuentro, lúcido, aunque borroso.

Esto significa que más allá de la dimensión racional del intelecto humano el afecto se integra en la dimensión intelectiva, ya que: este signo puede ser dirigido al-ad-afecto, que lo repleta con un gozo inexplicable, que a nosotros es imposible concebir. Desde este punto de vista el autor evoca las palabras sonoras; de ahí también las afecciones del alma, porque no pueden expresar, designan a través de cosas internas, así como el júbilo, del que se dice en el salmo respecto de aquello: "Asciende a Dios en júbilo", que "es el gozo inefable, que no puede callarse ni expresarse (80). Llama la atención la relevancia de la voz del otro, a la cual se une el júbilo. Sin embargo, también esto cabe trascender, como dice Alberto, cuando insiste: o como el-ad-intelecto, según el cual concibe algo de Dios, y en cuanto a

(78) 460, 63-74: quod contemplatio dei dupliciter potest considerari: vel quantum ad id in quo contemplamur deum, sive quantum ad principium contemplationis, et sic loquitur Dionysius in Caelesti Hierarchia, quod non possumus videre divinum radium in hac vita sine velamine signorum et effectuum, quia "videmus nunc per speculum et in aenigmate"; vel quantum ad finem contemplationis sive quantum ad id quo per contemplationem quaerimus, et sic est ipse deus nonvelatus, ad quod in ultimo nostri pervenimus, in quo intellectuales naturas attingimus; frustra enim esset ratiocinativa inquisitio, nisi perveniret ad intellectivam unitionem.

(79) 460, 81-461, 2: Ad tertium dicendum, quod est pertransire aliquid contemplatione dupliciter: vel quantum ad vim contemplativam, et sic neque transcendere neque aequare possumus angelos in hac vita, quamvis per lumen divinum elevemur supra facultatem nostrae naturae, vel quantum ad obiectum contemplationis, et sic, quia quod quaerimus, super omnia est, ipsos etiam angelos contemplando transimus, sicut in CANTICO dicitur: "Paululum cum pertransissem eos, inveni, quem diligit anima mea".

(80) 461, 19-26: Et hoc signum vel est ad affectum qui impletur gaudio inexplicabili, et quod etiam concipi non potest, et quantum ad hoc dicit sonos; unde etiam affectiones animi, quia exprimi non possunt, interiectionibus significantur, sicut est iubilus, de quo DICITUR super illud PSALMI: "Ascendit deum in iubilo", quod "est ineffabile gaudium, quod nec taceri potest nec exprimi valet". 
esto dice sermones, que son voces que experimentan el concepto de la mente; y todo esto se debe trascender, porque nada de ellos es el objeto que buscamos por la contemplación (81).

Pero ¿qué significa esto respecto de las fuerzas naturales? (82) Comenta Alberto:... hay que decir que el que contempla es separado también de las fuerzas naturales, no en cuanto al-ad-uso de ellas, sino en cuanto a-ad-sus operaciones, entonces, porque no son intensos actos de ellos mismos, y por eso esto consume a la vez en ellos el nutrimento, y pueden mucho ayunar (83). A través del ejemplo del sueño el autor explica la relevancia del exceso también a nivel de las fuerzas naturales, a la inversa, pues, hay que decir que aquello es verdadero en las potencias sensitivas, que a causa de lo que es material accesorio en los órganos, se destruye por la corrupción de los órganos a partir de lo que excede lo sensible; y el mismo Filósofo también dice que no es tal respecto del intelecto, que como acepta máximamente lo inteligible, no puede aceptar lo mínimo, sino más. Y por eso, el intelecto no se corrompe, sino que se robustece a partir de-ad-la unión con la luz divina. Tal vez se debe decir que si también se corromperá la unión con la excelente luz por las disposiciones naturales, porque de dicho modo se une a sí mismo, siendo elevado por las disposiciones sobrenaturales encima de su naturaleza, de nuevo no se corrompe, sino se perfecciona (84). La unión con la luz divina se produce a partir del exceso, que no es corrupción, sino perfección de las disposiciones naturales del intelecto elevado a la contemplación encima de su propia naturaleza

De hecho, la perfección se acrecienta cada vez más respecto a lo desconocido en sí, el intelecto no se une bien, pero por lo más conocido en sí y lo desconocido para nosotros se une óptimamente, porque por la unión a-ad-su mismo conocimiento de sí adquiere más y más, y tal desconocido es Dios (85). Puede apreciarse así que el modo negativo y sobrenatural por conocer a Dios completa el esfuerzo del intelecto natural a través de un exceso permanente más allá de los límites distintos, de tal modo que el origen fundante divino se configura en la realidad creada a modo del speculum aeternitatis (86).

(81) 461, 26-30: vel est ad intellectum, secundum quod concipit aliquid de deo, et quantum ad hoc dicit sermones, qui sunt voces exprimentes conceptum mentis; et haec omnia oportet transcendere, quia nullum eorum est obiectum, quod quaerimus contemplatione.

(82) Cf. 461,39; 462, 27.

(83) 463, 15-21: quod contemplator segregatur etiam a virtutibus naturalibus, non quantum ad usum ipsarum, sed quantum ad actum, tum quia non sunt intensi actus ipsarum, et propter hoc parum consumitur in eis de nutrimento, et multum possunt ieiunare.

(84) 463, 58-70: quod illud verum est in potentiis sensitivis, quae propter hoc quod materiales sunt et organis affixae, destruuntur per corruptionem organorum ab excellenti sensibili; et ipse PHILOSOPHUS etiam dicit, quod non est ita de intellectu, qui cum accipit maxime intelligibilia, non minus accipere potest minima, sed magis. Et ideo intellectus non corrumpitur, sed roboratur ex unitione ad lumen divinum. Vel dicendum, quod si etiam corrumperetur unitus excellenti lumini naturalibus dispositionibus, quia tamen unitur sibi supernaturalibus dispositionibus elevantibus eum supra suam naturam, iterum non corrumpitur, sed perficitur.

(85) 463, 71-75: quod ignoto in se non bene unitur intellectus, sed notissimo in se et ignoto nobis optime unitur, quia per unitionem ad ipsum cognitionem ipsius acquirit magis ac magis, et tale ignotum est deus...

(86) ANZULEWICZ H., De forma resultante in speculo. Die theologische Relevanz des Bildbegriffs und des Spiegelbildmodells in den Frühwerken des Albertus Magnus, II.Teil(Beiträge zur Geschichte der Philosophie und Theologie des Mittelalters, Neue Folge, 53/II)Münster 1999, 273-284. 


\section{c) El speculum aeternitatis}

Cuando Alberto pone fin a su explicación del primer capítulo de su Comentario, realiza un giro llamativo, al referirse al speculum aeternitatis. Este, pues, "a modo de espejo" insinúa el Misterio en cuanto origen fundante de alteridad, que se va gestando desde el más allá - patria- en el más acá de la vida presente -in via-, por ser Dios el Otro por excelencia. El autor parte del ejemplo de Moisés, quien parece vio al mismo Dios. Alberto acota y explica: el mismo Dios pues es visto por la visión, que es cara a cara, porque esta es prometida en la Patria por el Apóstol 1 Co 13, 12; pero Moisés ve así, porque dice de Él, Ex 33, 11, 13: "Hablaba, sin embargo, el Señor a Moisés cara a-ad-cara”, de otro modo se hubiese frustrado su oración, porque esto mismo pidió, diciendo: "Muéstrame tu rostro"; por eso parece que vio al mismo Dios (87). Alberto contrapone la visión de Dios in patria de 1 Co 13, 12 con la in via de Ex 33, 11, preguntando por la posibilidad de ver o no a Dios mismo en esta vida.

Emerge así la pregunta, ¿de qué modo puede ser que alguien contemple a Dios por la contemplación más noble si no ve al mismo Dios, así como Moisés contemplaba, y como en nosotros concurre lo plural en las intelecciones naturales, así, la abstracción de la especie a los fantasmas y -ad-la unión al-ad-intelecto posible y la ilustración del intelecto agente, a estos se asimila aquel conocimiento de la contemplación tan sublime? (88). Cuando Alberto pregunta aquí por un tipo de "especie", constitutivo de todo conocimiento natural, esboza una solución a partir de los presupuestos filosóficos propios, la distinción entre el intelecto posible y el intelecto agente, es decir, la recepción pasiva se torna activa en la visión de Dios.

Tal distinción la profundiza Alberto por medio de otra distinción, que emerge entre lo temporal y lo eterno y cuya dualidad relacional afina aquella, pues: ...el ver la cara es doble: es decir, en sí, privado de velo, y de esta manera se verá la faz de Dios en la patria, pero así no vio Moisés, sino Su faz en los signos de cualquier efecto de lo divino, que Dionisio llama aquí rationes subiectas, y allí son llamadas las espaldas de Dios; de ahí, pues, que el Señor le dice a-ad-él: "verás mi espalda, pero mi cara no podrás ver" (89). En la doble significación del ver la cara, Alberto interrelaciona la expresión "ver de espaldas" con las razones subyacentes de Dionisio.

De esta manera, el autor recurre al conocimiento natural para dilucidar la proyección hacia la dimensión sobrenatural, que no puede concluirse a partir de los primeros

(87) 464, 9-17:Videtur, quod Moyses viderit ipsum deum; ipse enim deus visione, quae est facie ad faciem, quia ista promittitur nobis in patria ab Apostolo, 1COR XIII(12); sed Moyses vidit sic, quia dicitur de ipso EXOD.XXXIII(11.13): Loquebatur autem dominus ad Moysen facie ad faciem"; alioquin fuisset frustrata oratio sua, qua IBIDEM petiit dicens: "ostende mihi faciem tuam"; ergo videtur, quod viderit ipsum deum.

(88) 464, 18-25: quomodo potest esse, quod aliquis contempletur deum nobilissima contemplatione nec tamen videat ipsum deum, sicut Moyses contemplabatur, et cum in nobis concurrant plura in naturalibus intellectibus, scilicet abstractio speciei a phantasmatibus et unitio ad intellectum possibilem et illustratio intellectus agentis, cui horum similatur illa cognitio contemplationis tam sublimis.

(89) 464, 30-37 quod videre faciem est dupliciter: scilicet in se sine velamine, et sic videbitur facies dei in patria, et sic non vidit Moyses, sed vidit faciem in signis quibusdam divinorum effectuum, quae hic DIONYSIUS vocat rationes subiectas, et: IBI vocantur posteriora dei; unde dominus dixit ad eum: Videbis posteriora mea, faciem autem meam videre non poteris". 
principios por medio de la ciencia especulativa. Pero sí nuestro intelecto se une a-adella, aceptando los movimientos superiores; y así el alma se fortifica mucho más para-ad-conocer lo divino, según que la misma luz divina desciende a ella; y se une de uno u otro modo. Y esta luz se llama "el espejo de la eternidad", en el cual vieron los profetas, que no es Dios mismo, sino que viene de Dios y asimila por la ilustración del intelecto agente lo conocido sobrenaturalmente (90). Alberto completa el movimiento ascendente insuficiente de la ciencia especulativa por el movimiento descendente, concretado en el speculum aeternitatis, aquella luz en la cual vieron los profetas, es decir, Alberto pasa del plano filosófico al teológico. Este paso expresa de modo más fino que en "el espejo de la eternidad" los profetas pueden "ver lo que viene de Dios", "no a Dios mismo". Pero sí se produce una asimilación de lo conocido sobrenaturalmente por el intelecto agente, es decir, una participación connatural en la luz divina recibida, a modo de espejo, es decir, inverso.

Alberto pasa a explicitar tal participación al interior del método, que procede tanto enseñando como escuchando, en cuanto pertenece a la percepción de esta doctrina, y porque a partir de la percepción de esta doctrina se llega a la unión, que une con lo divino... por las negaciones a diferencia de -ad-las afirmaciones divinas (91). Resalta aquí la relevancia de la unión, en la cual confluyen lo humano y lo divino dentro de la diferencia metódica, basada en la oración, pues pedimos que podamos ver y conocer a Aquel mismo, donde se vacian todos nuestros conocimientos naturales, por el no-ver y no-saber, es decir, por algún camino ver y conocerlo a Él, que está encima de todos, etc. Esto es, Dios. Ver se refiere al-ad-simple intelecto intuitivo, que concierne a los principiantes, y conocer al-ad-conocimiento conclusivo, que se origina desde los principios; y según esto, Dios es conocido como Principio, cuando lo aceptamos a Él mismo como luz de nuestro intelecto, y por esta luz divina somos conducidos desde los divinos atributos a ciertas conclusiones, cuando lo conocemos como sabio, bueno, etc. (92). Resalta la distinción entre la luz en sí y la "luz participada"-lumen- por el intelecto a modo de oscuridad.

Alberto sitúa el intelecto, siguiendo a Dionisio, metódicamente, entre las negaciones y afirmaciones en cuanto doble movimiento, pues afirma el Doctor Universalis del Areopagita que: muestra la diversidad entre negaciones y afirmaciones divinas y

(90) 464, 50-58: unitur ad ea accipienda intellectus noster motoribus superioribus; et multo magis roboratur anima ad videnda divina, secundum quod ipsum divinum lumen descendit in ipsam; et forte coniungitur uterque modus. Et istud lumen vocatur speculum aeternitatis, in quo viderunt prophetae, quod non est deus, sed a deo, et assimilatur illustrationi intellectus agentis super naturaliter cognita.

(91) 465, 4-9: quantum pertinet ad perceptionem huius doctrinae, et quia ex perceptione huius doctrinae pervenitur ad unitionem, qua unimur divinis ideo in isto capitulo determinat modum quantum ad unitionem, quomodo scilicet oportet per intellectum uniri deo et voce laudare ipsum; 465, 14-15: in secunda ostendit differentiam negationum ad affirmationes divinas.

(92) 465, 18-32: Precamur nos fieri a deo in hac caligine in qua est deus, obscura quoad nos, superlucenti in se, et precamur in ipso non videre et non cognoscere, idest in hoc ipso, dum omnes naturales nostrae cognitiones vacant, per non-videre et ignorare sicut per quandam viam videre et cognoscere eum qui est super omnem etc. scilicet deum; et videre referatur ad simplicem intuitum intellectus, qui est principiorum, et cognoscere ad notitiam conclusionum, quae oriuntur ex principiis; et secundum hoc deus cognoscetur ut principium, quando accipimus ipsum ut lumen nostri intellectus, et per lumen divinum ducimur in divina attributa sicut in conclusiones quasdam, dum cognoscimus eum sapientem, bonum etc. 
dice: las afirmaciones sobre Dios podemos comenzarlas desde las primeras y más nobles y por medio de ellas descendemos hasta-ad-las últimas (93). No cabe duda, el movimiento descendente, que completa el ascendente, tiene una singular importancia para Alberto, como puede apreciarse cuando se refiere a las negaciones en comparación con las afirmaciones, pues: en las negaciones respecto de Dios procede de modo inverso, porque es necesario para nosotros que negando la cosa de Dios, comencemos por los últimos, esto es, los más ínfimos y ascendamos por ellos hasta-ad- los supremos (94). Tal inversión ubica la búsqueda de una mayor intelección del misterio de Dios en el preciso punto de la confluencia de lo divino y lo humano.

Esta confluencia, por su parte, se caracteriza por una doble distinción, pues: Hay que decir que en Dios están libres todos los modos de conocer que son naturales en nosotros, por los cuales adquirimos las ciencias; Dios, en efecto, no es conocido por Sí mismo como lo son los primeros principios, ni "a causa de algo" -propter-, porque no tiene causa, ni "porque" -quia-, ya que no tiene efecto proporcionado. Pero nuestra mente recibe alguna luz divina, que está encima de su naturaleza, que la eleva encima de todos los modos naturales de conocimiento y por aquello se llega al conocimiento de Dios, confusamente -confuse-todavía, y no determinantemente, conociendo "porque" -quia-. Y debido a eso, se dice que por el no-ver Dios es visto, es decir, el no-ver natural (95). Aquí se distingue entre el propter a causa- y quia -porque-. Esto, a su vez, conlleva la distinción entre lo natural y lo sobrenatural. Pues nuestra mente es elevada encima de las fuerzas naturales, como el autor afirma, cuando aborda el método de las afirmaciones. Por su parte, la distinción entre lo natural y sobrenatural se entreteje con la luz divina, participada, a modo de un no-ver, y como tal, es calificada de confusa.

El alma recibe alguna luz, que causa la no-visión, de modo natural, y esta luz abre un camino de acceso al conocimiento de Dios, de modo confuso, por lo cual el no-ver designa una vía de acceso a la luz de Dios (96). Pero ¿las creaturas tienen algún papel en este acceso? Alberto observa: Parece que las creaturas no estorban la visión divina; no es pues lo mismo ayudar y estorbar; pero las creaturas, como en ellas se encuentran el vestigio y la imagen de Dios, ayudan al conocimiento de Dios; por eso, no estorban (97). Pero contesta, hay que decir que la creatura puede

(93) 465, 53-60: ostendit diversitatem inter negationes et affirmationes divinas et dicit, quod in affirmationibus divinis inicipimus a primis et nobilioribus et per media descendimus usque ad ultima.

(94) 466, 1-3: in negationibus divinis est e contrario, quia oportet nos negando res a deo incipere $a b$ ultimis, idest ab infimis, et per principaliora ultimis, quae sunt media, ascendere ad extrema, idest ad summa.

(95) 466, 59-69: Dicendum, quod in deo vacant omnes modi cognoscendi paturales nobis, quibus scientias acquirimus; neque per se notus est sicut principia, neque "propter quid", quia non habet causam, neque "quia", quia non habet effectum proportionatum. Sed mens nostra suscipit quoddam lumen divinum, quod est supra naturam suam, quod elevat eam super omnes modus visionis naturales, et per illud venit ad visionem dei, confuse tamen et non determinante cognoscens "quia". Et ideo dicitur, quod per non-videre videtur deus, scilicet per non-videre naturale.

(96) Cf. 466, 72: dicendum, quod in anima suscipitur quoddam lumen, quod causat non-visionem secundum modos naturales, et illud lumen habet viam in confusam dei cognitionem, et secundum illud non-videre habet viam.

(97) 467, 13-16: Videtur, quod creaturae non officiant divinae visioni; non est enim idem adminiculans et officiens; sed creaturae, cum in eis sit vestigium et imago dei, adminiculantur ad dei cognitionem; ergo non officiunt. 
ser considerada de doble manera: o en razón de vestigio, en cuanto conduce a Dios, y así esto procura una ayuda para el conocimiento de Dios, considerado como Causa, o en cuanto procede de la diversidad en cuanto a la esencia, a la especie, al género y al principio, a la manera como el ente es común a la substancia y al accidente. En este último sentido, la creatura obstaculiza el conocimiento de Dios, tal como es visto por la Naturaleza Divina. Y este conocimiento lo califica el autor de visión pura, porque es sin referencia a los efectos que Él causa (98). Resalta la distinción entre el conocimiento por vestigio y el conocimiento por causa y efecto. Es el primero el que facilita el conocimiento de Dios, mientras el último lo obstaculiza, aunque es factible, si se presta atención a los pasos metódicos necesarios.

Alberto observa respecto del tipo de conocimiento por vía de la causa un doble movimiento, hay que decir que en el paso por la composición, que parte de las propiedades esenciales de la Realidad (divina), se procede por el modo de afirmación. En la vuelta al Principio simple, la serie que va del "ser-substancial" al "cuerpo" y del "cuerpo" al "animado", y de tal forma progresa hasta-ad-los atributos particulares, o por el recorrido a la inversa toma como sujetos los atributos afirmativos en el otro paso, porque ellos no son diversos en cuanto al ser. Pero por el paso por la composición, que va de la causa separada por la esencia en lo causado, se practica el método de la afirmación, porque así se manifiesta la Causa como causa, que en cuanto tal recibe la atribución de sus efectos. Por el contrario, por el regreso hacia la Causa, uno busca la misma esencia de la Causa, y por eso, como ella está separada de todo sus efectos, debe proceder por las negaciones (99). Se aprecia aquí, sin duda, la relevancia del conocimiento de la primera causa.

En efecto, la primera causa no es asequible por el camino de la simple afirmación, pero tampoco por la negación, pues: Hay que decir que la labor teológica explicada aquí no es de la manifestación de Dios en algún efecto o don suyo, sino como se manifiesta en sí, y esto es comprendido suficientemente, en cuanto a-ad-las afirmaciones en estos tres libros, porque algo se dice de Dios (100). Respecto a esta manifestación de Dios "en sî", que aquí resalta, Alberto da un paso más, cuando insiste en la dificultad que encuentra el método al tratar las personas divinas, que Dionisio había abordado en su libro Theologicis hypotyposibus (101), pues primero dice en el libro que está hecha de las divinas personas, que máximamente alabamos

(98) 467, 33.-40: Dicendum ad primum, quod creatura potest dupliciter considerari: aut in ratione vestigii inquantum ducit in deum, et sic confert ad cognotionem ipsius, qua cognoscitur ut causa, aut inquantum procedit in diversitate essentiae et speciei et generis et principii, sicut ens est commune substantiae et accidenti, et hoc modo officit ad cognitionem ipsius, qua videtur in sua natura. Et hanc cognitionem vocat mundam visionem, quia sine respectu ad causata.

(99) 467, 41-52. Dicendum, quod in via compositionis ex essentialibus rei proceditur affirmando et similiter in resolutione, sicut de substantia in corpus et de hoc in animal et sic usque ad individua praedicando et e converso subiciendo, quia non differunt per essentiam. Sed in via compositionis, quae est de causa separata per essentiam in causata, est modus affirmationis, quia sic manifestatur causa ut causa, quae inquantum huius recipit praedicationem effectuum, sed per reditum in ipsam quaeritur ipsa essentia causae, et ideo, cum sit separata ab omnibus causatis, oportet, ut per negationes procedatur.

(100) 468, 46-50: quod theologicum negotium dicitur hic, non quo manifestatur deus in aliud effectu vel dono suo, sed quod manifestatur in se, et hoc sufficienter comprehenditur quantum ad affirmationes in his tribus libris, quia aliquid dicitur de deo.

(101) Se trata aquí de una de las pocas menciones de tal obra dionisiana, que no se sabe si es auténtica. 
las afirmaciones divinas, que pertenecen propiamente a-ad-las personas, esto es, de qué modo la divina y buena naturaleza está calificada en singular (102). Alberto destaca aquí las personas divinas y su interrelación con la naturaleza divina, buena y singular.

Esta naturaleza divina emerge del origen trinitario, pues: hay que decir que el Bien aquí se entiende por la naturaleza divina, según que ella está en el Padre, que es el principio de la generación, porque el Padre genera por el poder de su naturaleza, que también, según lo que es considerado por sí mismo, es absoluta y está en los tres. En la medida en que está referida al acto de la generación, ella es considerada únicamente en el Padre y está dicho como relación a-ad-otro-aliquid-, del mismo modo que es calificada potencia generante. Lo que por eso se objeta en el primer argumento, es que el nombre del Bien es una denominación del orden de la esencia; se debe decir, lo que es verdadero, también porque significa la esencia concreta en su supuesto. Por eso, puede ser entendido de manera indirecta al sentido del sujeto, de la persona (del Padre), todo como se dice también con la fórmula "Dios de Dios" (103). Resalta aquí la índole relativa de la generación -ad aliquiden cuanto relacion a otro, lo cual plasma el misterio de la alteridad en sí y como tal conocido (104).

Esto explicita la fórmula Dios de Dios, pues: hay que decir, que la emanación de los afectos o pensamientos se efectúa sobre el modo inmaterial a partir del corazón. Por lo mismo, para-ad-significar la inmaterialidad de la generación divina se asimila naturaleza divina y corazón, según lo que es en el Padre el principio de la procesión del Hijo y del Espíritu Santo, y porque las procesiones emanan del Padre y por eso permanece en su esencia, ya que se dice: todo permanece en su corazón -manentia in corde (105). Alberto llega aquí a la mayor profundidad, que subraya, cuando se refiere "a las luces" dionisianas, de esta manera las luces no se ponen para-ad-demostrar la perfección de las personas divinas, sino para-ad-que deba ser declarada la procesion formal de las mismas, porque así como la luz es de la luz, así Dios es de Dios (106).

(102) 469, 24-28: Dicit ergo primo: Igitur in Theologicis hypotyposibus, idest in libro, quem fecit de divinis personis, maxime laudamus----propria affirmativae theologiae, idest affirmationes divinas, quae proprie pertinent ad personas, scilicet quomodo divina et bona natura dicitur singularis,

(103) 469, 68-78: Et dicendum ad primum, quod bonum hic sumitur pro divina natura, secundum quod est in patre principium generationis, quia pater generat virtute naturae, quae quidem, secundum quod per se consideratur, est absolutum et est in tribus, secundum autem quod refert ad actum generationis, est tantum in patre et dicitur ad aliquid, sicut etiam dicitur de potentia generandi. Quod ergo obicit, quod est essentiale nomen bonum, dicendum: quod verum est, tamen quia significat essentiam concretive in supposito(et) ideo potest trahi ex adiuncto ad supponendum pro persona, sicut dicitur etiam "deus de deo".

(104) EMERY G., La relation dans la théologie de S. Albert le Grand, en SENNER W., ANZULEWICZ H.(eds.), Albertus Magnus. Zum Gedenken nach 800 Jahren:Neue Zugänge, Aspekte und Perspektiven, Berlin 2001, 455-465.

(105) 469, 79- 470, 2: dicendum, quod quia processio affectionum vel cogitationum est a corde immaterialitatem divinae generationis assimilatur divina natura cordi, secundum quod est in patre principium processionis filii et spiritus sancti, et quia procedunt personaliter a patre et tamen manent in essentia sua, ideo dicuntur manentia in corde.

(106) 470, 3-6: quod lumina ponit non ad demostrandum perfectionem divinarum personarum, sed ad declarandum processionem formalem ipsarum, quia sicut lumen est de lumine, ita deus de deo. 
Alberto explicita esta verdad en estrecha interrelación con la espiración del Espíritu Santo: en el corazón, en cuanto permanecen en una esencia, según que una y otra de las personas permanece, según que el Hijo está en el Padre y el Padre en el Hijo, al modo como una persona procede de otra por la propagación coeterna-coaeterna pullulatione-, porque la generación del Hijo no precede a la espiración del Espíritu, ni la espiración del Espíritu precede a la generación del Hijo, porque no hay un paso de las potencias al acto, y también, como Jesús es supraesencial en cuanto a la divinidad, está constituido en su realidad substancial, permaneciendo en las verdaderas propiedades de la naturaleza humana, esto es, de cuerpo verdadero y de alma verdadera, y todo lo otro expresado (107).

Estas afirmaciones las precisa Alberto cuando se refiere a Dios intelecto, que no es lo que se logra captar de la mente humana, pues: Se asciende de nuevo desde lo sensible a-ad-lo inteligible, decimos, que Dios no es ni alma en cuanto a-ad-la parte inferior, según lo que anima el cuerpo, ni es mente en cuanto a-ad-la parte superior, que es el ojo del alma, según lo cual la mente es llamada a partir de la medida, o el alma se refiere a los hombres, la mente a los ángeles (108). Para Alberto es evidente que la mediación no tiene cabida en Dios en el sentido de la estructura propia del conocimiento natural.

Por eso, vale que para conocer a Dios no es ni la opinión, que es la aceptación por signos y, por eso, bajo el aspecto de contrario; ni la razón, que resuelve los signos exteriores en principios intrínsecamente esenciales; o el intelecto, que se encuentra en la misma esencia de la cosa y en los principios primeros como términos de la razón; ni es algo de ellos, ni es decible ni el quid inteligible o el quia determinante, sino un tanto confuso-confuse-, ni es el número ni el orden, que sigue al número, en el cual hay primero y posterior, ni la magnitud, esto es, espiritual, y de modo semejante hay que entender a partir de todo lo que sigue (109). Alberto resalta así al finalizar su Comentario no solo la confluencia de lo racional e intelectual, lo exterior y lo interior, sino advierte también el dinamismo del prius et posterius que no es de Dios.

Esto significa que para conocer la profundidad trinitaria solo resta tocarla, lo cual se produce en una gran felicidad, como dice Agustín: tocar con la mente a Dios es felicidad grande, y el tacto se refiere a-ad-los principios; ni la ciencia para-adlas conclusiones, ni la verdad, según lo que se opone a lo falso por el aspecto a-ad-

(107) 470, 7-20: Deinde dicit: Et etiam, quomodo permanserunt inegressibilia a mansione in ipso, scilicet corde, inquantum manent in una essentia, et in seipsis, secundum quod unaquaeque personarum manet in se, et in se invicem, secundum quod filius est in patre et patre in filio, quamvis una persona procedat ab alia coaterna pullatione, quia generatio filium non praecedit nec spiratio spiritum sanctum, quia non est exitus de potentia ad actum, et etiam, quomodo Iesus supersubstantialis, quantum ad divinitatem, est factus substantia, manens in veritatibus humanae naturae, scilicet veri corporis et verae animae, et quaecumque alia expressa ab eloquiiis. Estos misterios son enseñados por las Palabras esto es, en los libros canónicos, todo esto es alabado in Theologicis hypotysibus.

(108) 474, 50-56: Dicit ergo primo: Rursus ascendentes a sensibilius ad intelligibilia dicimus, quod deus non est anima quantum ad inferiorem partem, secundum quod animat corpus, neque mens quantum ad superiorem partem, qui est oculus animae, secundum quod mens dicitur a metiendo; vel anima referatur ad homines, mens ad angelos.

(109) 474, 85-88: neque est aliquid eorum, neque dicibile est neque intelligibile "quid" vel "quia" determinante, sed confuse tantum, neque numerus est neque ordo, qui consequitur numerum. 
la cosa, porque es la adecuación entre realidad e intelecto, y lo demás: por sí mismo es patente (110). El autor define el tacto como un "referirse a los principios", más allá de la adaequatio rei et intellectu, definición que no se usa literalmente, sino como punto de partida dentro del contexto de la argumentación. De esta manera, toda la búsqueda desemboca en la alabanza, que se nutre del exceso, en cuanto supera toda negación y afirmación: Y por eso ni negaciones ni afirmaciones son suficientes para su alabanza, cuya virtud y magnificencia y eternidad son infinitas por todos los siglos de los siglos. Amén (111).

En síntesis, llama la atención que la fórmula inicial que define el misterio se invierte desde lo más oscuro o menos oscuro en "más o menos claro". Esta inversión confirma que a Alberto le interesa la luz y no, como a Dionisio, el "Dios oculto". Por medio de esta luz el hombre participa, jubilosamente, en el Misterio del DiosOtro, en cuanto es relación tanto ad intra como ad extra.

\section{A MODO DE CONCLUSIÓN}

Si bien la alteridad emerge con fuerza del Comentario de Alberto a la Mystica Theologiae de Dionisio, sigue siendo un misterio, que se articula desde la complejidad de la presencia del Dios oculto hasta su mayor profundidad en la simplicidad de la inexistencia de una persona divina en la otra, origen último de todo otro que anticipa al sujeto y lo constituye en su mismidad, semejante a como el maestro se relaciona con el discípulo, en cuanto expresión de la relación del Hijo para con el Padre en el Espíritu. Como tal, la argumentación puesta a descubierto responde a las aporías que los recientes estudios de Weber y Hoye dejaron abiertas, cuando se centran o en el amor o en la razón, sin que logren articular la inexistencia de aquel en ella, constituyendo así el misterio de la alteridad la solución del problema planteado, es decir, para Alberto, el intelecto es amor.

En efecto, la "luz de la fe", que Weber propone como solución, tiene mucho a favor de expuesto, presta atención a la índole cognoscitiva, que a primera vista domina en el comentario, siendo, de hecho, frecuente la recurrencia a la metáfora y al concepto de la luz; la fe, por su parte, rescata aquel énfasis en lo sobrenatural, que Alberto vuelve a destacar una u otra vez. Pero, de hecho, ambas dimensiones mencionadas encuentran una mejor articulación por medio de la alteridad en las facetas analizadas, pero también por la del misterio que, por un lado rompe contornos, por otro los concretiza, de modo inaudito, en el misterio del Verbo. De todos modos, por ambos lados se obtiene una mayor nitidez, sobre todo en lo que se refiere a la índole de relación, teniendo esta su punto de gravitación en el ad-aliquid trinitario.

La solución intelectualista de Hoye, por su parte, logra desvelar acertadamente el movimiento del intelecto a través de sus momentos claves, pero se detiene allí

(110) 475, 7-11: Augustinus, quod attingere mente deum magna est beatitudo et tactus tunc referatur ad principia; neque scientia ad conclusiones, neque veritas, secundum quod opponitur falso per respectum ad res, quia "est adaequatio rei et intellectus"

(111) 475, 34-37: Et ideo neque negationes neque affirmationes pertingunt ad sufficientiam laudis ipsius cuius est virtus et magnificentia infinita et aeternitas per omnia saecula saeculorum Amen. 
donde la alteridad permite avanzar, es decir, lleva la constitución dual del intelecto en cuanto posible y agente hasta su mayor connaturalidad en su origen intratrinitario, que trasunta "de modo confuso" en la situación del hombre in via, en la cual irrumpe la realidad divina a partir del speculum aeternitatis.

Lo decisivo que aporta el misterio de la alteridad proviene, sin embargo, del hecho de que dicho misterio articula connaturalmente lo racional y afectivo para una inexistencia, que a la vez es relación y substancia, es tanto afecto como intelecto, amor como razón, está hecho y por hacerse, don sublime delimitado, y determinación indebida gratuita, alteridad y ipseidad, aunque a modo de espejo, pero siempre creatural, también en la visión cara a cara. Efectivamente, los adversarios de Alberto son aquellos autores que intuyen algo muy cierto, pero al separar amor y razón no advierten que la realidad se constituye de modo dual, es decir, tanto a nivel óntico como práctico, la alteridad es decisiva.

Sin duda cuesta desvelar las finuras de la argumentación albertina, no solo cuando el autor se distancia de Dionisio, pese a que le sigue siendo fiel, sino también porque propone un enfoque teológico propio y original, más allá de una simple paráfrasis del texto dionisiano, un negotium theologicum a partir de la experiencia mística, orientada por la salvación y como tal de una singular actualidad hoy. La resistencia que manifiesta cualquier estudiante de postgrado frente a tal quehacer teológico no sorprende, ya que dicho quehacer parece tan diferente a como solemos hacer teología hoy, y, sin embargo, resulta imposible escapar a su fascinación y relevancia permanente. En este sentido, quisiera agradecer a los jóvenes inquietos y rebeldes la resistencia, que manifestaron durante un semestre de trabajo intenso, a entrar en la "tiniebla espesa", aunque siempre "luminosa", porque lograron convencerse de que la teología o es mística o no es teología.

\section{RESUMEN}

La alteridad constituye una realidad compleja, que desde siempre suscita interés, debido a que su extraña densidad conceptual tiene una singular repercusión vital. Si bien ella emerge con fuerza del Comentario de Alberto a la Mystica Theologiae de Dionisio, sigue siendo un misterio, que se articula desde la complejidad de la presencia del Dios oculto hasta su mayor profundidad en la simplicidad de la inexistencia de una persona divina en la otra, origen último de todo otro que anticipa al sujeto y lo constituye en su mismidad, semejante a como el maestro se relaciona con el discípulo, en cuanto expresión de la relación del Hijo para con el Padre en el Espíritu. Como tal, la argumentación puesta a descubierto en el presente estudio responde a las aporías que los recientes estudios de Edouard Henry Weber y William Hoye dejaron abiertas, cuando se centran o en el amor o en la razón, sin que logren articular la inexistencia de aquel en ella, constituyendo así el misterio de la alteridad la solución del problema planteado, es decir, para Alberto, el intelecto es amor.

\section{ABSTRACT}

Alterity constitutes a complex reality, one that has always aroused interest, owing to a singular vital repercussion of its strange conceptual density. Although it emerges strongly in 
Albert's commentary on Dionysius' Mystica Theologiae, it continues being a mystery that articulates itself from the complexity of the presence of the hidden God up to its greatest profundity in the simplicity of the "in-existence" of one divine person in the other, ultimate origin of every other that anticipates the subject and constitutes it in its selfness, similar to how the teacher relates to his or her disciple, inasmuch as it is an expression of the relation of the Son towards the Father in the Spirit. As such, the argument placed before us in this present study responds to the aporias that the recent studies by Edouard-Henry Weber and William Hoye left open, when they are centered either on love or on reason, without managing to articulate the "in-existence" of that in it, thus constituting the mystery of alterity as the solution to the problem presented-that is to say, for Albert, the intellect is love. 